\title{
Application of Chiral Ionic Liquids for Asymmetric Induction in Catalysis
}

\author{
Martin H. G. Prechtt ${ }^{*, a}$, Jackson D. Scholten ${ }^{\mathrm{a}}$, Brenno A. D. Neto ${ }^{\mathrm{b}}$ and Jairton Dupont ${ }^{\mathrm{a}}$ \\ ${ }^{a}$ Universidade Federal do Rio Grande do Sul (UFRGS), Institute of Chemistry - Campus do Vale, Laboratory of Mo- \\ lecular Catalysis, Avenida Bento Gonçalves 9500 (P.O. Box 15003), Porto Alegre - RS - Brazil, CEP 91501-970 \\ ${ }^{b}$ Laboratory of Medicinal and Technological Chemistry, University of Brasília (IQ-UnB), Brasília, DF, Campus Univer- \\ sitário Darcy Ribeiro (P.O.Box 4478), Brasília - DF-Brazil, CEP 72919-970
}

\begin{abstract}
Here we present the state-of-the-art for asymmetric catalysis using chiral ionic liquids (CILs) as source of chiral information. The current review covers reactions using typical homogeneous catalysts e.g. organocatalysts, transition metal complexes and solid catalysts for heterogeneous catalysis in solvent-systems with chiral ionic liquids.
\end{abstract}

\section{INTRODUCTION}

Most of the chemical production processes in industry involve catalysts $(>90 \%)$ and the majority are heterogeneous processes [1]. This is due to practical aspects like purification of products or intermediates. However, solid catalysts are disadvantageous if asymmetric reactions such as asymmetric hydrogenation need to be carried out. In that case, chiral organometallic complexes or organocatalysts acting in homogeneous manner are clearly superior to the heterogeneous type of catalyst. Further attempts for asymmetric induction in principle use substrates, reagents and auxiliaries bearing the chiral information successfully [2], or chiral reaction media, the latter one less successfully [3]. Other investigations involved asymmetric induction by chiral particles of achiral substances, like chiral quartz $\left(\mathrm{SiO}_{2}\right)$ or glycine crystals, for example in asymmetric photochemical reactions in the solid state $[4,5]$. In the absence of chiral molecules also circularly polarized light can be used as chiral force such as the synthesis of hexahelicene with left or right circularly polarized light $[4,5]$.

There are reports though, which are describing the immobilization of chiral homogeneous catalyst on solid support [6]. However, in most cases homogeneous catalysts do not fulfill the necessary requirements (catalyst stability, catalyst recycling, separation from product and intermediates) for industrial processes like continuous-flow processes. For years, the industrial adaptation only seemed practical if homogeneous catalysts are immobilized on solid supports or soluble polymers which can be easily separated from solution [6]. Combining the advantages of solid catalysts (stability, recyclable, purification, long life-time) $[6,7]$ and the advantages of homogeneous catalysts (chemo-, regio- and asymmetric reaction controls) [6, 7] lead to chiral ionic liquids (CILs) as an reaction media for the immobilization of the catalyst. Nowadays, CILs seem to be the most adequate

\footnotetext{
*Address correspondence to this author at the Universidade Federal do Rio Grande do Sul (UFRGS), Institute of Chemistry - Campus do Vale, Laboratory of Molecular Catalysis, Avenida Bento Gonçalves 9500 (P.O. Box 15003), Porto Alegre - RS - Brazil, CEP 91501-970, Brazil; Fax: +49-32124702238; E-mail: martin-prechtl@gmx.net
}

materials potentially fulfilling all the desired requirements for a heterogeneous-type solid catalyst as well as typical molecular complex catalysts or organocatalysts for asymmetric catalysis. Recently, their unique material and solvent properties and the growing interest in a sustainable, "green" chemistry has led to an amazing increase in interest in such salts [8].

Ionic liquids (ILs) are well-organized three-dimensional media. It has been shown that intramolecular $\mathrm{C}-\mathrm{H} \bullet \bullet \pi$ interactions results in a well-organized $3 D$ structure where ionic channels are formed by cations and anions [9]. This supramolecular arrangement render them in a plethora of applications and opportunities [10]: a media for metal nanoparticles formation and stabilization [11], the formation of organized liquid clathrates [12], and in many different physicochemical processes [13]. There are many different reviews on the subject of ILs that can attend many readers with distinctive needs [14].

Not before 1999 the first CIL, an imidazolium salt with a lactate as chiral anion was published by Seddon, and in the following years most of the CILs had chiral cations derived from the "chiral pool" [15]. Their chirality origin is from axial, central or planar chirality. Additionally, it can be found in both cation, and the anion - the so called doubly chiral IL. As a consequence of a very well organized $3 D$ structure, CILs have an intrinsic potential for enantioselective reactions, especially because in a well organized media it is reasonable to expect some chiral transmission. Whether considering that ILs can participate in the transition state or stabilizing charged (or polar) intermediates, it is expected that chiral induction takes place in that media.

The chiral transmission using CILs as the single source of chirality may take place through two different pathways: (1) the CILs indeed participate in the reaction intermediates or transition states [16], e.g. some proline TSCILs (taskspecific CIL) and (2) through ion-pairing formation [17].

The attempts to use chiral solvents as source of chirality goes back to the 1970s, when Seebach and Oei performed electrochemical reduction of ketones in a chiral amino ether which led to a rather low enantioselectivity of $\sim 24 \%$ ee [18]. Further investigations in the past decades gave also comparably low asymmetric induction which resulted in the ac- 
cepted conclusion that chirality transfer from chiral solvents is rather low [3]. Later on, it was not necessary to wait again several decades for further advantages in catalysis using chiral solvent. This conclusion seemed to be unchanged at least until middle of 2004. Then, the first motivating result was published by Vo-Thanh and coworkers [19]. The middle of May 2006 can be dated as the breakthrough of catalysis using CIL as single source of chirality. Almost parallel Leitner [20], Afonso [21], Malhotra [22], Cheng [23], and all their respectively coworkers presented their contribution to this research field with remarkably high enantiomeric excesses in different reactions. Nowadays, many applications of CILs in different areas of research may be found in the open literature. CILs are used for enantioselective separation of pharmaceutical products by capillary electrophoresis,[24] to tune some kinetics aspects on the asymmetric hydrogenation of some specific compounds [25], chiral stationary phase for the liquid chromatographic resolution [26], enantiomeric recognition properties [27], influence on the excitedstate properties [28], and others. Furthermore, the importance of CILs are reflected in various publications showing simply their syntheses, characterizations and properties $[29$, $30,31]$ Several reviews can be found describing the development in the syntheses and applications of CILs [15]. In the present review we focus on the application of CILs in asymmetric catalysis and not on the synthesis/design of CILs which are more intensively discussed in previous reviews [15].

\section{ORGANOCATALYSIS}

\subsection{Baylis-Hillman Reaction}

Vo-Thanh and coworkers presented the pioneering work about a DABCO (1,4-diazabicyclo[2.2.2]octane) catalyzed asymmetric Baylis-Hillman reaction between benzaldehyde and methyl acrylate 3 (Scheme 1, Table 1). Enantioselectivities up to $44 \%$ ee were obtained using a chiral cation, based on ephedrine, as source of chirality [19].

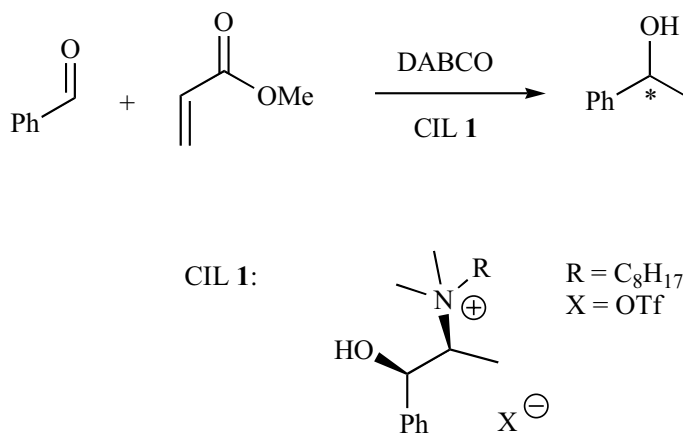

Scheme 1. Asymmetric induction by the CIL 1 in a Baylis-Hillman reaction (up to $44 \%$ ee) [19].

They pointed out the necessity of an excess of the CIL 1 to obtain an enhanced enantioselectivity but this was accompanied by an decreasing yield. The latter one was explained by the insolubility of benzaldehyde under the reaction conditions. Furthermore, no influence to the enantiomeric excess was recognized using different alkyl chain lengths in the IL. Instead, the choice of the anion seems to play an important role, in the decomposition pathway of the CIL, where the IL 1 with the triflate anion is superior towards the stability of the CIL [32]. Furthermore, the alcohol function in the IL is propitious for the chirality transfer, using a CIL with an ester group the enantiomeric excess dropped to $6 \% e e$. They presumed, that the $\mathrm{OH}$ group acts as a coordination point for a carbonyl function in the substrate via hydrogen bridges. Noteworthy, unmodified ephedrine as chiral catalyst gave only $9 \%$ ee.

Table 1. Asymmetric Baylis-Hillmann Reaction in the Presence of Chiral IL 1 [19]

\begin{tabular}{|c|c|c|c|c|}
\hline Entry & IL 1 (eq.) & Conversion (\%) & Yield (\%) $^{\mathbf{a}}$ & $(\boldsymbol{R}) \mathbf{- 1} \boldsymbol{e e ~ ( \% )})^{\mathbf{b}}$ \\
\hline \hline 1 & 0.5 & 86 & 76 & 20 \\
\hline 2 & 1 & 85 & 78 & 23 \\
\hline 3 & 1.5 & 85 & 73 & 28 \\
\hline 4 & 3 & 65 & 45 & 32 \\
\hline 5 & 3 & 88 & 60 & $44^{\mathrm{c}}$ \\
\hline
\end{tabular}

Conditions: benzaldehyde:methyl acrylate: $\mathrm{DABCO}=1: 1: 1$.

$\mathrm{T}=30{ }^{\circ} \mathrm{C}, \mathrm{t}=4$ days. ${ }^{\mathrm{a}}$ Determined by GC; ${ }^{\mathrm{b}}$ determined by chiral HPLC; ${ }^{\mathrm{c}} \mathrm{t}$ $=7$ days.

Leitner presented an enantioselective Aza-BaylisHillman reaction with enantiomeric excesses up to $84 \% e e$ in CIL with nucleophilic Lewis-bases as organocatalysts [20]. These results stay in one row with the best results obtained in conventional solvents ( $94 \%$ ee and $83 \%$ ee) [33]. In contrast to Vo-Thanh, they used a chiral anion derived from the chiral pool (Scheme 2).

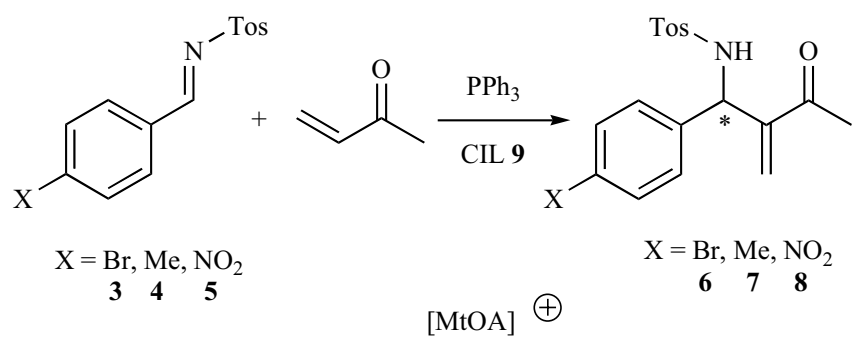

CIL 9:<smiles>O=C(O)C[C@H]1O[B-]2(OC1=O)OC(=O)[C@@H](CC(=O)O)O2</smiles>

Scheme 2. Enantioselective aza-Baylis-Hillman reaction (up to $84 \%$ ee). $[\mathrm{MtOA}]^{+}=$Methyltrioctyl ammonium [20].

In their investigations they also confirmed the mentioned importance of $\mathrm{OH}$ groups as hydrogen-bond donors for the stability of reaction intermediates. So, $\mathrm{OH}$ groups in alcohol and acid functionalities can indeed act as a coordination point between the CIL and a carbonyl group in the reactants. Though, this allows asymmetric induction into the reactants. Noteworthy, dilution experiments in conventional organic solvents with equivalent amounts of CIL resulted in racemic products, and this indicates the necessity to use the CIL as solvent for effective chirality transfer. 

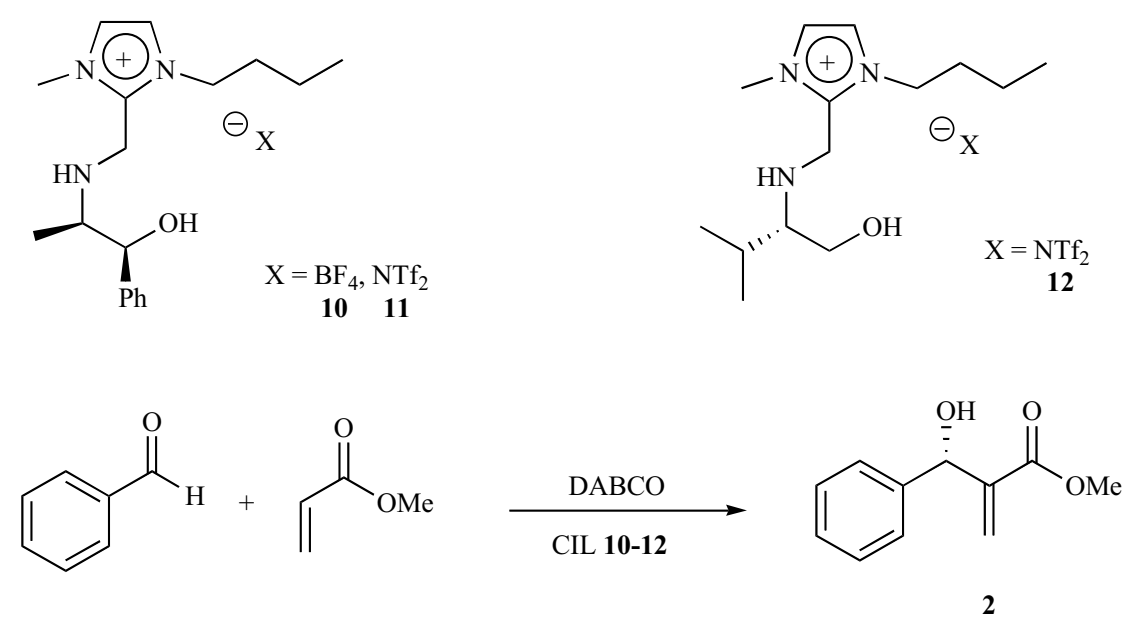

Scheme 3. Asymmetric version of the Baylis-Hillman reaction using CILs [34].

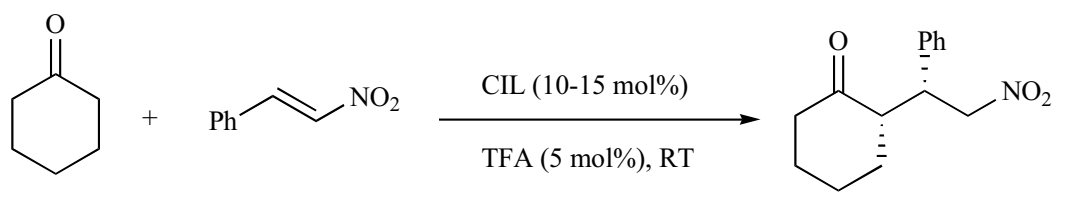

14

Best CIL: $\quad 100 \%$ yield, syn:anti $=99: 1,99 \% e e$

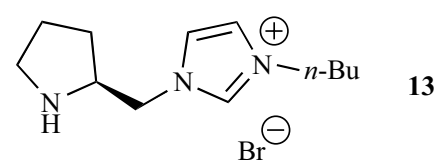

Scheme 4. Asymmetric nitro-aldol reaction with chiral TSIL-catalysts [23].

Following Vo-Thanh's attempts to induce chirality in Baylis-Hillman reaction, Headley and co-workers presented novel CILs 10-12 for this application (Scheme 3) [34].

In many examples, a co-solvent were used yielding the Bailys-Hillman adduct in reasonable yields (5-80\%) and 0$14 \%$ of enantiomeric excess. However, without the presence of a co-solvent (using pure CILs), the author got the best yields $(80-82 \%)$ and the best enantiomeric excess $(5-25 \%)$. The best reaction conditions (CIL 10, $4{ }^{\circ} \mathrm{C}$ and 7 days) were tested using different aldehydes and acrylates. Yields were moderate to high (38-91\%) but enantiomeric excess $(2-24 \%)$ were fairly low.

\section{MICHAEL ADDITION REACTION}

The first approach to use typical organocatalysts incorporated in CILs for enantioselective catalysis was presented by Cheng and co-workers [16c, 23]. In contrast to the previously discussed asymmetric catalyses in here, they incorporated directly typical chiral organocatalysts into side-chains to generate chiral functional ionic liquids (FILs) as taskspecific ILs (TSILs). Those TSILs were used as organocatalysts (10-15 mol\%) for Michael addition of nitroolefins with TFA (trifluoroacetic acid) as co-catalyst (5 mol\%), (Scheme 4).
In most cases the yields were up to quantitative and the enantiomeric excesses were usually over $90 \%$ ee, with some exceptions (lowest ee: $70 \%$ ). In contrast to the previously discussed results, here, Cheng et al. observed that incorporation of protic groups (hydrogen bond donors) in the CILs resulted in a decrease of activity and selectivity. Otherwise in accordance to the observation by Afonso [21], and Malhotra [22], they also recognized a strong influence of (achiral) anions onto the transfer of the chiral information. Concerning activity and selectivity the $\mathrm{PF}_{6}$-anion is the less recommendable anion due to lower yields and enantiomeric excesses. The group also recycled their chiral TSIL-catalysts by precipitation in five successful runs with high enantioselectivities and high yields. Advanced studies showed that salicylic acid gives also good results as co-catalyst in combination with a CIL 15 bearing a benzimidazolium-backbone (Scheme 5, Table 2) [16c].

A novel type of pyrrolidine-based chiral ILs with chirality on the cation was developed by Headley et al. to catalyze the Michael addition of aldehydes and nitrostyrenes. Using these ILs as organocatalysts, it is possible to obtain products in high diastereoselectivities, good enantioselectivities and moderate yields (depending on the groups $R_{1}$ and $R_{2}$ ) with a good recyclability of the system (Scheme $\mathbf{6}$ and Table $\mathbf{3}$ ) [35]. 
<smiles>[R]C1CCC(=O)CC1</smiles>

CIL 15:

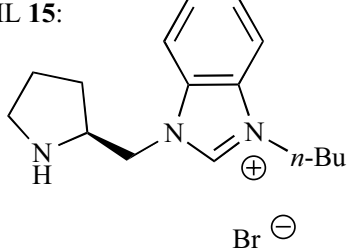

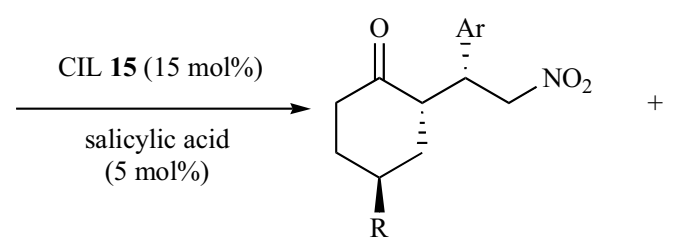

(a)<smiles>[R]C1CCC(=O)[C@H]([Al]C[N+](=O)[O-])C1</smiles>

(b)

16a-21a

16b-21b

$\mathrm{R}=\mathrm{Me} ; \mathrm{Ar}=\mathrm{Ph}: \mathbf{1 6}$

$\mathrm{R}=\mathrm{Me} ; \mathrm{Ar}=4-\mathrm{ClPh}: \mathbf{1 7}$

$\mathrm{R}=\mathrm{Me} ; \mathrm{Ar}=2-\mathrm{ClPh}: \mathbf{1 8}$

$\mathrm{R}=\mathrm{Me} ; \mathrm{Ar}=2-\mathrm{O}_{2} \mathrm{NPh}: 19$

$\mathrm{R}=t-\mathrm{Bu} ; \mathrm{Ar}=\mathrm{Ph}: \mathbf{2 0}$

$\mathrm{R}=\mathrm{Ph} ; \mathrm{Ar}=\mathrm{Ph}: \mathbf{2 1}$

Scheme 5. Asymmetric Michael addition catalyzed by CIL 15 (15 mol\%) and salicylic acid as co-catalyst (5 mol\%) [16c].

Table 2. Asymmetric Michael Addition Catalyzed by CIL (15 mol\%) and Salicylic Acid as co-catalyst (5 mol\%) [16c]

\begin{tabular}{|c|c|c|c|c|c|c|}
\hline Entry & $\mathbf{R}$ & Ar & t (h) & Yield $(\%)^{\mathrm{a}}$ & $d r(\mathbf{a}: \mathbf{b})^{\mathrm{b}}$ & $e e(\%)^{\mathrm{c}}$ \\
\hline 1 & $\mathrm{Me}$ & $\mathrm{Ph}$ & 10 & 89 & $6.2: 1$ & 97 \\
\hline 2 & $\mathrm{Me}$ & 4-ClPh & 10 & 89 & $6.1: 1$ & 99 \\
\hline 3 & $\mathrm{Me}$ & 2-ClPh & 10 & 99 & $>10: 1$ & 97 \\
\hline 4 & $\mathrm{Me}$ & $2-\mathrm{NO}_{2} \mathrm{Ph}$ & 3 & 93 & $4.4: 1$ & 97 \\
\hline 5 & $t-\mathrm{Bu}$ & $\mathrm{Ph}$ & 12 & 88 & 7.9:1 & 98 \\
\hline 6 & $\mathrm{Ph}$ & $\mathrm{Ph}$ & 10 & 63 & $12: 1$ & 96 \\
\hline
\end{tabular}

${ }^{\mathrm{a}}$ Isolated yields; ${ }^{\mathrm{b}}$ determined by ${ }^{\mathrm{l}} \mathrm{H}$ NMR; ${ }^{\mathrm{c}}$ determined by chiral HPLC.

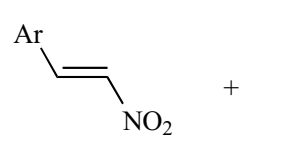

$\overbrace{\mathrm{R}_{2}}^{\mathrm{O}} \mathrm{R}_{1}$

$\underset{\mathrm{Et}_{2} \mathrm{O}, 4{ }^{\circ} \mathrm{C}, 6 \text { days }}{\mathrm{CIL} 22(20 \mathrm{~mol} \%)}$

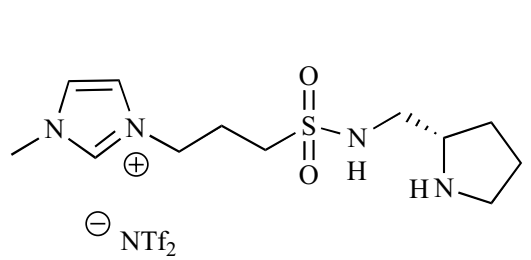

$\mathrm{R}_{1}=n-\mathrm{Bu} ; \mathrm{R}_{2}=\mathrm{H} ; \mathrm{Ar}=\mathrm{Ph}: \mathbf{2 3}$

$\mathrm{R}_{1}=n-\mathrm{Bu} ; \mathrm{R}_{2}=\mathrm{H} ; \mathrm{Ar}=p$-Tol: 24

$\mathrm{R}_{1}=\mathrm{R}_{2}=\mathrm{Me} ; \mathrm{Ar}=\mathrm{Ph}: \mathbf{2 5}$

$\mathrm{R}_{1}=n-\mathrm{Pr} ; \mathrm{R}_{2}=\mathrm{H} ; \mathrm{Ar}=\mathrm{Ph}: \mathbf{2 6}$

$\mathrm{R}_{1}=i-\operatorname{Pr} ; \mathrm{R}_{2}=\mathrm{H} ; \mathrm{Ar}=\mathrm{Ph}: 27$

CIL $22=$ $\Theta_{\mathrm{NTf}_{2}}$

Scheme 6. Pyrrolidine-based CIL employed as catalysts in asymmetric Michael addition [35].

A mild and efficient procedure for asymmetric Michael additions of cyclohexanone to chalcones catalyzed by an amino acid IL $\mathbf{2 8}$ was investigated (Scheme 7, Table 4) [36]. The authors used here directly the proline-anion as chiral catalyst with an imidazolium-cation as counterion.

In a general way, yields were reasonable (30-96\%), and diastereomeric ratios moderate to very good (20:80 to $4: 96$ favoring syn isomer). Enantiomeric excesses ranged from
$17-94 \%$. To achieve better results, the author performed the reaction in methanol as a solvent. It is worth noting that the use of DMSO as a solvent gave the product with the inverse configuration. However, the most interesting aspect of the study was an unexpected solvent-dependent inversion of the enantioselectivity using $\mathrm{MeOH}$ and DMSO. Further investigations are necessary to understand these unexpected results. 
Table 3. Asymmetric Michael Additions of Aldehydes and Nitrostyrenes Using CIL 22 as Catalysts at $4{ }^{\circ} \mathrm{C}$ [35]

\begin{tabular}{|c|c|c|c|c|c|c|}
\hline Entry & $\mathbf{R}_{1}$ & $\mathbf{R}_{2}$ & Ar & Yield (\%) & Syn/Anti & $e e(\%)$ \\
\hline 1 & $n-\mathrm{Bu}$ & $\mathrm{H}$ & $\mathrm{Ph}$ & 64 & $97: 3$ & 68 \\
\hline 3 & $\mathrm{Me}$ & $\mathrm{Me}$ & $\mathrm{Ph}$ & 58 & ---- & 82 \\
\hline 4 & $n-\operatorname{Pr}$ & $\mathrm{H}$ & $\mathrm{Ph}$ & 49 & $89: 11$ & 64 \\
\hline
\end{tabular}
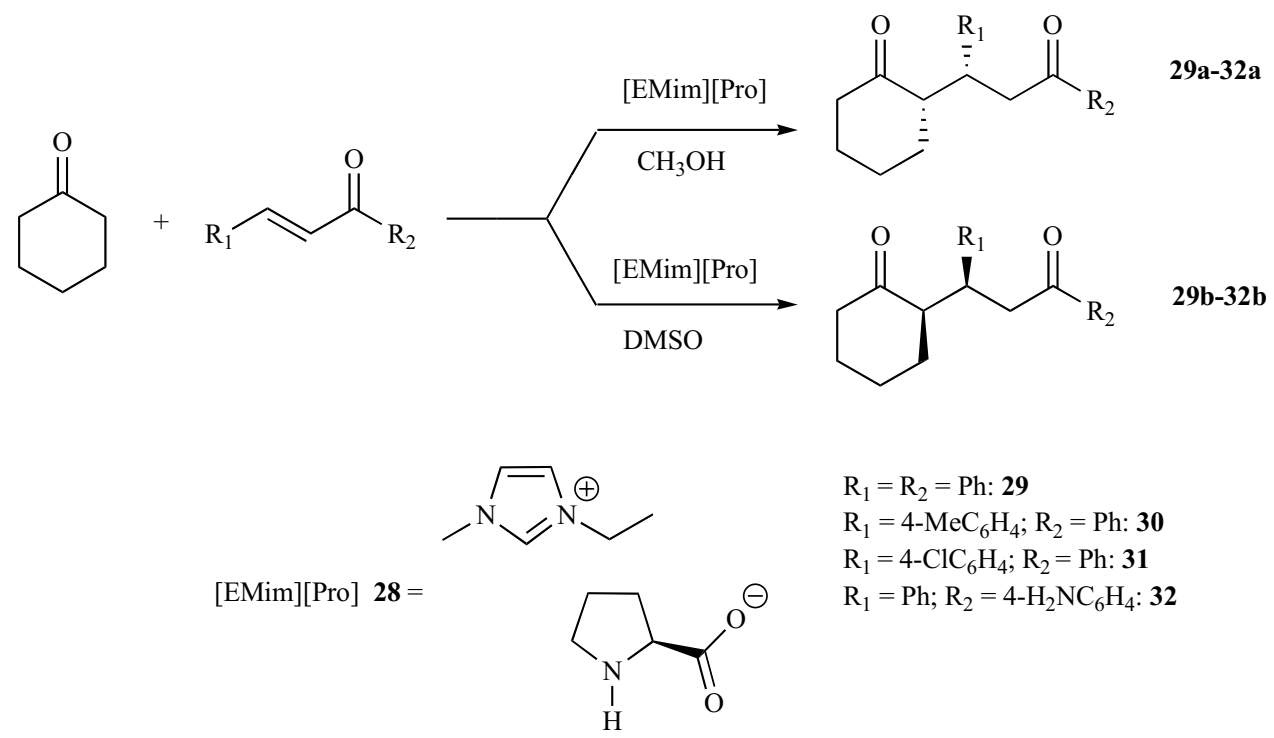

$$
\begin{aligned}
& \mathrm{R}_{1}=\mathrm{R}_{2}=\mathrm{Ph}: \mathbf{2 9} \\
& \mathrm{R}_{1}=4-\mathrm{MeC}_{6} \mathrm{H}_{4} ; \mathrm{R}_{2}=\mathrm{Ph}: \mathbf{3 0} \\
& \mathrm{R}_{1}=4-\mathrm{ClC}_{6} \mathrm{H}_{4} ; \mathrm{R}_{2}=\mathrm{Ph}: \mathbf{3 1} \\
& \mathrm{R}_{1}=\mathrm{Ph} ; \mathrm{R}_{2}=4-\mathrm{H}_{2} \mathrm{NC}_{6} \mathrm{H}_{4}: \mathbf{3 2}
\end{aligned}
$$

\begin{tabular}{|c|c|c|c|c|c|c|c|}
\hline Entry & $\mathbf{R}_{1}$ & $\mathbf{R}_{\mathbf{2}}$ & Solvent & t (h) & Yield (\%) & Anti/Syn ${ }^{b}$ & $e e(\%)^{\mathrm{b}}$ \\
\hline 3 & $4-\mathrm{ClC}_{6} \mathrm{H}_{4}$ & $\mathrm{Ph}$ & $\mathrm{CH}_{3} \mathrm{OH}$ & 4 & 98 & 4:96 & 60 \\
\hline 4 & $\mathrm{Ph}$ & 4- $\mathrm{NH}_{2} \mathrm{C}_{6} \mathrm{H}_{4}$ & $\mathrm{CH}_{3} \mathrm{OH}$ & 8 & 87 & $4: 96$ & 94 \\
\hline 6 & 4- $\mathrm{MeC}_{6} \mathrm{H}_{4}$ & $\mathrm{Ph}$ & DMSO & 4 & 98 & $16: 84$ & -72 \\
\hline 7 & $4-\mathrm{ClC}_{6} \mathrm{H}_{4}$ & $\mathrm{Ph}$ & DMSO & 4 & 94 & $10: 90$ & -65 \\
\hline 8 & $\mathrm{Ph}$ & $4-\mathrm{NH}_{2} \mathrm{C}_{6} \mathrm{H}_{4}$ & DMSO & 8 & 85 & 4:96 & -91 \\
\hline
\end{tabular}

Scheme 7. Asymmetric Michael addition using a CIL bearing a chiral anion [36].

Table 4. Asymmetric Michael Addition of Cyclohexanone and Chalcones Catalyzed by a CIL 28 at Room Temperature (Selected Data) [36]

${ }^{\mathrm{a}}$ Isolated yield; ${ }^{\mathrm{b}} d r$ and $e e$ determined by HPLC. The signal (-) means inversion of configuration.

In further works, some pyrrolidine-based chiral pyridinium ILs 33-36 were synthesized and tested as efficient promoters of the asymmetric Michael addition (Scheme 8, Table 5) [37]. These CILs 33-36 have been found to be recyclable and efficient organocatalysts for the addition reactions of ketones to nitroolefins with high yields, high enantioselectivities, and diastereoselectivities.
The obtained yields were higher than $74 \%$ and diastereomeric ratios over 95:5 favouring the $s y n$-isomer. Additionally, the enantiomeric excesses of the major isomer were higher than $86 \%$. The best condition developed required $5 \mathrm{~mol} \%$ of trifluoroacetic acid at a temperature of 4 ${ }^{\circ} \mathrm{C}$. 

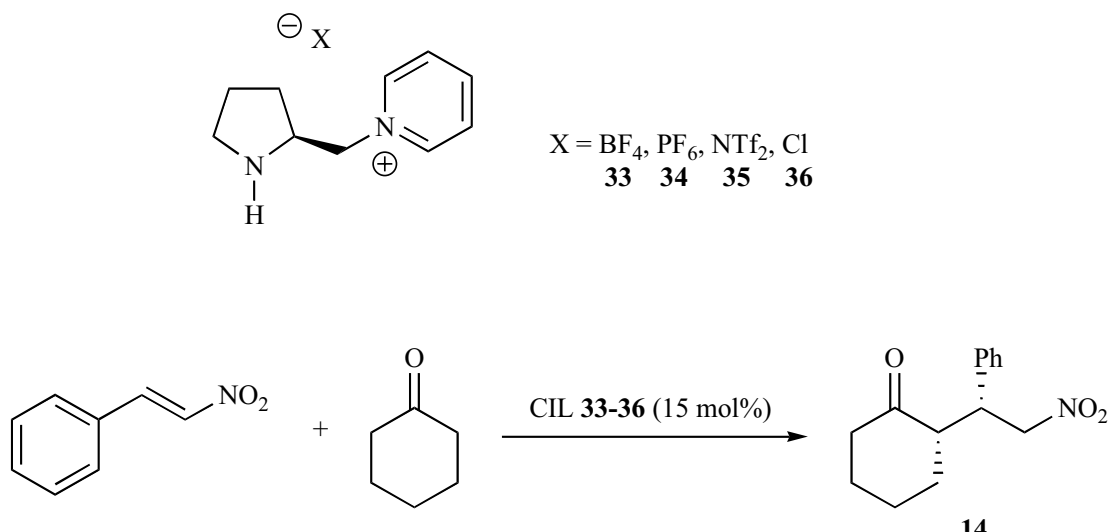

14

Scheme 8. Asymmetric Michael reaction using CILs 33-36 [37].

Table 5. Michael Reaction between Cyclohexanone and Nitrostyrene with CILs 33-36 at Room Temperature (Selected Data) [37]

\begin{tabular}{|c|c|c|c|c|c|c|}
\hline Entry & Catalyst & TFA $(\operatorname{mol} \%)^{a}$ & t (h) & Yield $(\%)^{b}$ & $e e, \operatorname{syn}(\%)^{\mathrm{c}}$ & Syn/Anti ${ }^{\mathrm{C}}$ \\
\hline 1 & 36 & ---- & 36 & 74 & 99 & $98: 2$ \\
\hline 2 & 36 & 5 & 36 & 91 & 99 & $97: 3$ \\
\hline 3 & 33 & --- & 36 & 75 & 94 & $>99: 1$ \\
\hline 4 & 33 & 5 & 16 & 95 & 98 & $99: 1$ \\
\hline 5 & 34 & --- & 72 & 90 & 93 & $99: 1$ \\
\hline 6 & 34 & 5 & 48 & 92 & 86 & $95: 5$ \\
\hline 7 & 35 & ---- & 43 & 81 & 95 & $96: 4$ \\
\hline 8 & 35 & 5 & 16 & 95 & 93 & $96: 4$ \\
\hline $9^{\mathrm{e}}$ & 33 & 5 & 30 & 92 & 99 & $>99: 1$ \\
\hline
\end{tabular}

${ }^{\mathrm{a}} \mathrm{TFA}$ (trifluoroacetic acid); ${ }^{\mathrm{b}}$ isolated yield; ${ }^{\mathrm{c}}$ determined by HPLC; ${ }^{\mathrm{d}}$ determined by ${ }^{1} \mathrm{H} \mathrm{NMR} ;{ }^{\mathrm{e}} \mathrm{T}=4{ }^{\circ} \mathrm{C}$.<smiles>[R]CC([R])=O</smiles>

38-44

$\operatorname{CIL} 37=$

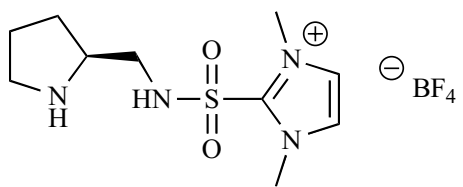

Scheme 9. CIL supported pyrrolidine sulfonamide organocatalyst 37 for the asymmetric Michael reaction [38].

A new class of CIL supported $(S)$-pyrrolidine sulfonamide organocatalyst $\mathbf{3 7}$ was developed by Headley and coworkers and shown to be a very effective catalyst for the asymmetric Michael addition reactions of ketones and aldehyde with nitroolefines with high enantio- and diastereoselectivities (Scheme 9, Table 6) [38].

Reactions yields ranged from $10-95 \%$ and in almost all cases an organic solvent was present in the reaction media. The authors obtained very good diastereoselectivity for all reactions favoring the $s y n$ isomer (up to 99:1), with ee ranging from 14 to $99 \%$. A series of different aldehydes were also tested under the best reaction conditions with high yields, diastereo- and enantioselectivity.

From the same group, further results were published in this area with pyrrolidine-based functionalized CILs and showing to be effective and reusable organocatalysts for the asymmetric Michael addition reactions of aldehydes with nitrostyrenes (Scheme 10, Table 7) [39]. 
Table 6. Asymmetric Michael Addition of Ketones and Nitro Olefins Catalyzed by CIL 37 (Selected Data) [38]

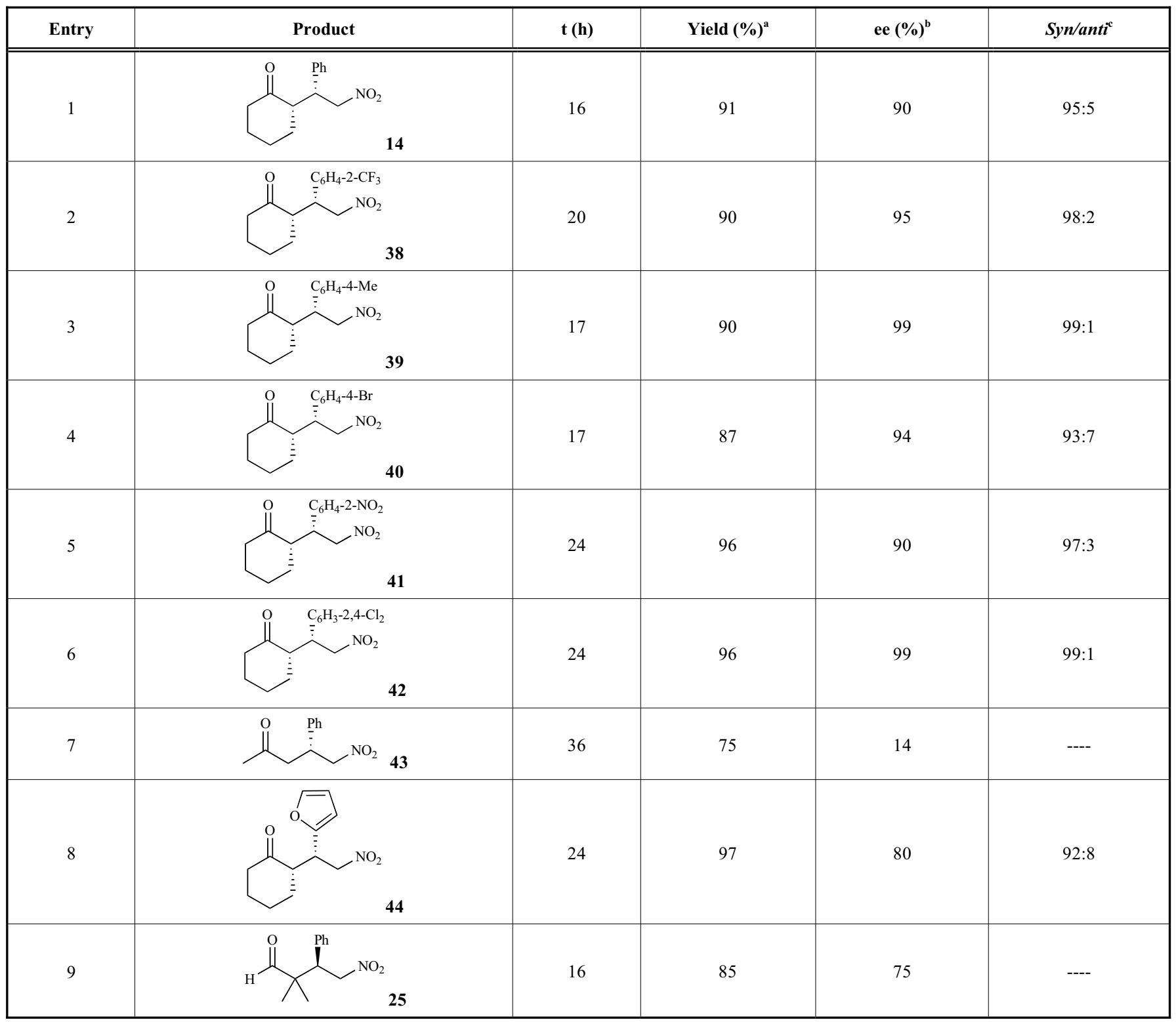

${ }^{\mathrm{a}}$ Isolated yield; ${ }^{\mathrm{b}}$ determined by chiral HPLC; ${ }^{\mathrm{c}}$ determined by ${ }^{\mathrm{l}} \mathrm{H}$ NMR.

$\Theta \mathrm{NTf}_{2}$<smiles></smiles>

45<smiles>O=[N+]([O-])C=Cc1ccccc1</smiles><smiles>CC(C)C=O</smiles>

$\ominus \mathrm{NTf}_{2}$<smiles></smiles>

46<smiles>CC(C)(C=O)[C@H](Cc1ccccc1)[N+](=O)[O-]</smiles>

Scheme 10. Asymmetric Michael Addition using a functionalized CIL 45-46 [39].

In many cases, the authors used an organic solvent to perform the reaction. Yields varied from 5-90\%. Enantiomeric excess could not be determined in some cases, while in other cases, it was above $80 \%$. It was also tested the reaction of cyclohexanone with nitrostyrene catalyzed by both CILs $\mathbf{( 4 5 ,}$ 46). In this case, these organocatalysts result in high yields (up to $99 \%$ ), good enantioselectivities (up to $85 \%$ ), and high diastereoselectivities (syn/anti ratio up to 97:3). It is worth 
Table 7. Asymmetric Michael Addition of Dimethylacetaldehyde with Nitrostyrene (Scheme 10) Catalyzed by a CILs $45 / 46$ at Room Temperature (Selected Data) [39]

\begin{tabular}{|c|c|c|c|c|c|c|}
\hline Entry & Solvent & Additive & Catalyst & t (days) & Yield $(\%)^{\mathrm{a}}$ & $e e(\%)^{\mathrm{b}}$ \\
\hline 1 & $\mathrm{MeOH}$ & ---- & 45 & 6 & 80 & 67 \\
\hline 2 & $\mathrm{MeOH}$ & $5 \%$ TFA & 45 & 6 & $<5$ & N. D. \\
\hline 3 & THF & ---- & 45 & 6 & 17 & 75 \\
\hline 4 & THF & $5 \% \mathrm{TsOH}$ & 45 & 6 & $<10$ & N. D. \\
\hline 5 & $\mathrm{MeOH}$ & ---- & 46 & 6 & 86 & 79 \\
\hline 6 & $\mathrm{MeOH}$ & $5 \%$ TFA & 46 & 3 & 90 & 84 \\
\hline
\end{tabular}

${ }^{\mathrm{a}}$ Isolated yield; ${ }^{\mathrm{b}}$ determined by HPLC analysis; N. D. = not determined.

$(\mathrm{TsOH}=p$-toluenesulfonic acid)
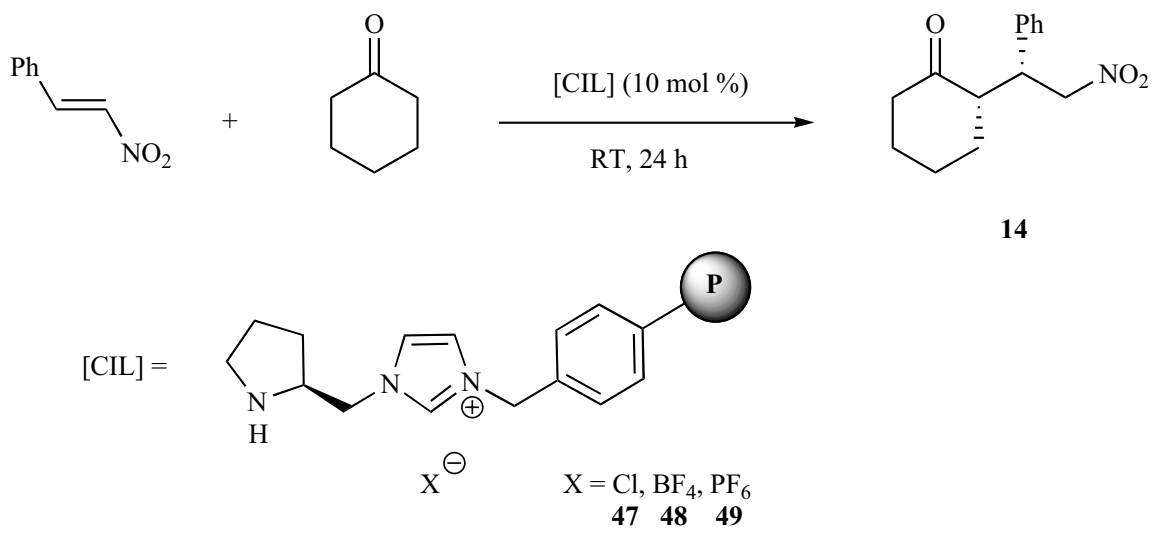

Scheme 11. Asymmetric Michael addition reactions catalyzed by the CILs 47-49 [40].<smiles></smiles><smiles>FC1O[Si]2(CCC[n+]3ccn(C[C@@H]4CCCN4)c3)OCC1O2</smiles><smiles>O=C1CCCCC1C(=O)C1CCCCC1[C@H](CO)c1ccccc1[N+](=O)[O-]</smiles>

14

Scheme 12. Asymmetric Michael addition using a silica-gel supported CIL [41].

noting that despite the fact that the best conversion was obtained using methanol as the solvent, the use of ether as the solvent gave the best ee $(82 \%)$ at temperature of $4{ }^{\circ} \mathrm{C}$, without the presence of any acid as additive.

Following in the field of organocatalysis, Wang et al. published the synthesis of polymer-bound pyrrolidine-based chiral ILs 47-49 and their application as catalysts in the asymmetric Michael addition reactions (Scheme 11) obtaining high yields $(>91 \%)$ and both excellent enantioselectivities $(>99 \% e e)$ and diastereoselectivities $(>99: 1 d r)[40]$.

Noteworthy, these reactions can be carried out under solvent-free conditions and the catalyst could be reused several times without loss in its catalytic activity. 
Table 8. Selected Examples of the Asymmetric Michael Reactions of Nitrostyrene with Cyclohexanone in Different Solvents Catalyzed by CIL at Room Temperature in $36 \mathrm{~h}$ [41]

\begin{tabular}{|c|c|c|c|c|c|}
\hline Entry & CIL & Solvent & Yield $(\%)^{a}$ & $e e(\%)^{\mathrm{b}}$ & $d r^{\mathrm{c}}$ \\
\hline 1 & 50 & $\mathrm{EtOH}$ & 71 & 98 & $99: 1$ \\
\hline 2 & 50 & $\mathrm{EtOH}$ & 68 & 97 & $99: 1$ \\
\hline 3 & 50 & DMF & 76 & 98 & $98: 2$ \\
\hline 4 & 51 & DMF & 72 & 98 & $98: 2$ \\
\hline 5 & 50 & $\mathrm{CH}_{2} \mathrm{Cl}_{2}$ & 61 & 98 & $98: 2$ \\
\hline 6 & 51 & $\mathrm{CH}_{2} \mathrm{Cl}_{2}$ & 56 & 96 & $98: 2$ \\
\hline 7 & 50 & $\mathrm{H}_{2} \mathrm{O}$ & 51 & 98 & $98: 2$ \\
\hline 8 & 50 & Hexane & 72 & 98 & $98: 2$ \\
\hline 9 & 50 & Neat & 91 & 99 & $99: 1$ \\
\hline
\end{tabular}

${ }^{\mathrm{a}}$ Isolated yields; ${ }^{\mathrm{b}}$ determined by HPLC; ${ }^{\mathrm{c}}$ diastereomeric ratio $d r$ (syn/anti) determined by ${ }^{1} \mathrm{H}$ NMR.<smiles></smiles><smiles>[R16][AsH2]C</smiles><smiles>[R]C(O)CC(C)=O</smiles><smiles>Cn1cc[n+](CC(=O)O[C@H]2CN[C@H](C(=O)O)C2)c1</smiles>

$\Theta_{\mathrm{BF}_{4}}$

$[\mathrm{CIL}]=$

52<smiles>Cn1cc[n+](CCOC(=O)[C@@H]2CCCN2)c1</smiles>

Scheme 13. CIL-catalyzed asymmetric aldol reaction [45].

Further studies were published later on by the same group using silica gel supported pyrrolidine-based CIL (50, 51) as recyclable organocatalyst for asymmetric Michael addition to nitrostyrenes (Scheme 12, Table 8) [41].

The reactions generated the corresponding products in moderate to good yields (up to $91 \%$ ), excellent enantioselectivities ( $>96 \% e e$ ), and high diastereoselectivities (>98:2 $d r)$. In addition, the catalyst could be reused at least five times without a significant loss of catalytic activity and stereoselectivity. Both organocatalysts gave similar results, but a slight advantage using a propyl group as spacer could be noted.

Previously works on CIL-catalyzed Michael additions with organic co-solvents reported much lower enantiomeric excesses $(<15 \%$ [42], and $<25 \%$ [43], ). More recent examples for this reaction, can be found elsewhere [44].

\section{ALDOL REACTION}

In 2006, Chan and coworkers have described the syntheses of new proline-based CILs $(\mathbf{5 2}, \mathbf{5 3})$ and the application of these ILs in asymmetric aldol reaction between ketones and aldehydes under mild conditions (Scheme 13) [45]. In particular for the reaction of 4-cyanobenzaldehyde and acetone, the CIL 52 gave better results in yield (59\%) and ee (72\%) in contrast to those obtained with CIL 53 (10\% yield and $11 \%$ ee). Therefore, one may denote that the acidic proton of proline (CIL 52) have an important role in the catalytic aldol process. A few examples of this work are summarized in Table 9.

Zlotin et al., presented new chiral ionic liquids (60-64) with imidazolium or pyridinium cations bearing amino acid moieties. Such salts are capable to catalyze (15 mol\% CIL) the asymmetric aldol reaction between aldehydes and ke- 
Table 9. Asymmetric Direct Aldol Reactions of Different Aldehydes with Acetone Using The CIL 52 as Organocatalyst (Selected Data) [45]

\begin{tabular}{|c|c|c|c|}
\hline Entry & $\mathbf{R}$ & Yield (\%) & ee (\%) \\
\hline \hline 1 & $\mathrm{Ph}$ & 50 & 76 \\
\hline 2 & $\mathrm{Cy}$ & 43 & 85 \\
\hline 3 & $4-\mathrm{BrC}_{6} \mathrm{H}_{4}$ & 73 \\
\hline 4 & $2-\mathrm{ClC}_{6} \mathrm{H}_{4}$ & 58 & 71 \\
\hline 5 & $4-\mathrm{O}_{2} \mathrm{NC}_{6} \mathrm{H}_{4}$ & 92 & 85 \\
\hline 6 & $4-\mathrm{NCC}_{6} \mathrm{H}_{4}$ & 64 & 72 \\
\hline $7^{\mathrm{a}}$ & $4-\mathrm{NCC}_{6} \mathrm{H}_{4}$ & 59 & 10 \\
\hline
\end{tabular}

${ }^{\mathrm{a}}$ CIL 53 was used

Table 10. Selected Results of Asymmetric Aldol Reactions Using the Synthesized CILs (60-64) [46]

\begin{tabular}{|c|c|c|c|c|c|}
\hline Entry & Catalyst & $\mathbf{t}(\mathbf{h})$ & Conv. (\%) & Anti/Syn & $\boldsymbol{e e ~ ( a n t i , ~ \% ) ~}$ \\
\hline \hline 1 & 60 & 15 & $>99$ & $98: 2$ & -10 \\
\hline 2 & 61 & 15 & --- & $97: 3$ & 97 \\
\hline 3 & 62 & 15 & 84 & $87: 13$ & 91 \\
\hline 4 & 63 & 20 & 89 & $90: 10$ & 97 \\
\hline
\end{tabular}

The conversions and diastereomeric ratio were determined by ${ }^{1} \mathrm{H}$ NMR and the ee by HPLC.

tones in water at room-temperature (Table 10, Scheme 14) [46]. It was established that the hydrophobic alkyl groups available in the organocatalysts improved the reaction efficiency under the examined conditions. The catalyst with the anion $\mathrm{PF}_{6}{ }^{-}$can be readily regenerated and utilized multiply without a decline in the conversion, $d r$, and ee values.

All yields ranged from good to excellent (58-99\%). Both, diastereomeric and enantiomeric rates (favoring anti isomer) were very good ranging from $d r 87: 13$ to $98: 2$ and ee from $91 \%$ to $>99 \%$. Interestingly, the use of pyridinium-based CILs (61-64) gave better results than imidazolium-based. However, no significant difference was observed among them.

In a previous work by Zlotin and co-workers, similar proline based CILs also displayed a good efficiency to promote asymmetric aldol reaction (Scheme 15, Table 11) [47].

The observed conversions, nevertheless, were ranging from $20 \%$ to $95 \%$ with high diastereomeric (up to $97: 3$ - anti isomer) and enantiomeric excesses (80-99\%). One may note that the only difference was the anion effect associate with the aldol process, and the use of $\mathrm{PF}_{6}$-anion gave the best results in terms of selectivity. Recently, it has been described the pronounced anion effect in some cases [48].

Cheng and co-workers presented a combinatorial synthesis towards a CIL-library. They used reagents from the chiral pool and generated chiral cations and chiral anions (including zwitterionic compounds), via ring-opening alkylation of the corresponding cyclic sulfates and sulfamidates. Such CILs were tested as organocatalysts in asymmetric aldol reactions (Scheme 16, Table 12) [16b, 49].
It is worth noting that the use of doubly CILs gave good yields (up to 97\%) and poor anti-diastereomeric (from 50:50 to $70: 30)$ and enantiomeric excess $(7-55 \%$ for anti isomer and $4-73 \%$ to syn isomer). The CIL with the anion $o-$ carboxyl-benzoic acid $\mathbf{8 0}$ showed the best anti-selectivity (70:30) and ee (55\%, for the anti-isomer and $73 \%$ for the syn isomer).

Further examples for enantioselective aldol reaction with CILs as organocatalysts are published elsewhere [50, 51].

\section{HOMOGENEOUS TRANSITION METAL CA- TALYSIS}

Where Vo-Thanh and Leitner focussed on organocatalysis, Afonso and coworkers investigated transition metal catalysis with CIL (e. g. 84) as source of chirality [21, 52]. To obtain low melting point salts using anions from the chiral pool which usually form solid salts, they have chosen the $[d m g]$ cation tetra- $n$-hexyl-dimethylguanidinium which is less prone to crystallize (Scheme 17). For the evaluation of the CILs for asymmetric catalysis, rhodium catalyzed intramolecular carbenoid $\mathrm{C}-\mathrm{H}$ insertion (not shown here) and Sharpless asymmetric dihydroxylation using osmium catalysts were performed, the latter shown in Scheme 17.

In both reactions high to almost quantitative yields were obtained, but the enantioselectivities differs from each other extremely. In the dihydroxylation of alkene impressive $e e$ 's were obtained $(72 \%$ ee and $85 \%$ ee), otherwise lower selectivity in the $\mathrm{C}-\mathrm{H}$ insertion was obtained (27\% ee). Most no- 
<smiles>O=C1CCCCC1</smiles>

$\mathrm{CIL}=$<smiles></smiles>

60<smiles>O=C(CCCC[n+]1ccccc1)O[C@H]1CN[C@H](C(=O)O)C1</smiles>

61<smiles>CCCCC(CCCC)c1cc[n+](CCCCC(=O)O[C@H]2CN[C@@H](C(=O)O)C2)cc1</smiles><smiles>CCCCCc1cc[n+](CCCCC(=O)OC[C@H](N)C(=O)O)cc1</smiles>

63<smiles>CCCCC(CCCC)c1cc[n+](CCCCC(=O)O[C@H](C)[C@H](N)C(=O)O)cc1</smiles>

Scheme 14. Asymmetric aldol reaction (top) and selection of amino acid derived CILs 60-64 [46].<smiles>O=C1CCCCC1</smiles><smiles>[R]C=O</smiles><smiles>CC(C)(C)[Mg]O</smiles><smiles>[R]C(O)[C@H]1CCCCC1=O</smiles>

66-69

$$
\mathrm{CIL}=
$$
65<smiles>CC(C)n1cc[n+](CCCCC(=O)O[C@@H]2CN[C@H](C(=O)O)C2)c1</smiles><smiles></smiles>
$\mathrm{R}=p-\mathrm{CH}_{3} \mathrm{O}_{2} \mathrm{C}_{6} \mathrm{H}_{4}: 67$ $\mathrm{R}=\mathrm{C}_{6} \mathrm{H}_{5}: \mathbf{6 8}$ $\mathrm{R}=p-\mathrm{CH}_{3} \mathrm{OC}_{6} \mathrm{H}_{4}: 69$

Scheme 15. Catalytic asymmetric aldol reaction by proline-derived CILs [47]. 
Table 11. Catalytic Aldol Reactions of Cyclohexanone and Different Aldehydes with CIL as Organocatalysts in the presence of Water (Selected Data) [47]

\begin{tabular}{|c|c|c|c|c|c|}
\hline Entry & $\mathbf{R}$ & $\mathbf{t}(\mathbf{h})$ & Conv. (\%) & Anti/Syn & ee, anti (\%) \\
\hline \hline 1 & $p-\mathrm{NO}_{2} \mathrm{C}_{6} \mathrm{H}_{4}$ & 10 & $>95$ & $97: 3$ & $>99$ \\
\hline 2 & $p-\mathrm{CH}_{3} \mathrm{O}_{2} \mathrm{CC}_{6} \mathrm{H}_{4}$ & 86 & $93: 3$ & $>99$ \\
\hline 3 & $\mathrm{C}_{6} \mathrm{H}_{5}$ & 10 & 67 & $84: 16$ & 88 \\
\hline 4 & $p-\mathrm{CH}_{3} \mathrm{OC}_{6} \mathrm{H}_{4}$ & 36 & 20 & 80 \\
\hline
\end{tabular}

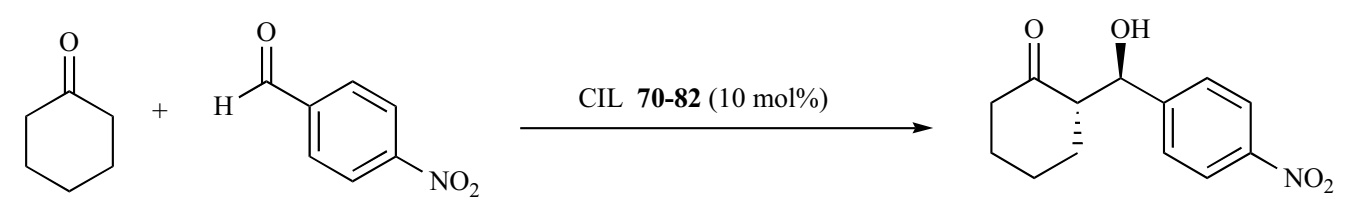

66

CIL:

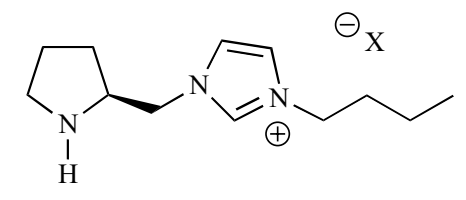

$\mathrm{X}^{-}=$<smiles>CC(C)C[C@H](N)C(=O)[O-]</smiles>

70<smiles>CC(C)C[C@H](N)C(=O)[O-]</smiles>

71<smiles>CC(C)[C@H](N)C(=O)[O-]</smiles>

72<smiles>CN(C)CC(=O)[O-]</smiles>

73

$$
\mathrm{N}_{3} \smile \mathrm{CO}_{2}^{-}
$$

74<smiles>O=C([O-])[C@@H](O)[C@@H](O)C(=O)O</smiles>

77<smiles>O=C([O-])c1ccccc1C(=O)O</smiles>

80<smiles>CN1CCC[C@H]1C=O</smiles>

75<smiles>O=C([O-])[C@@H](O)[C@H](O)C(=O)[O-]</smiles>

78<smiles>O=C(O)c1cccc(C(=O)O)c1</smiles>

81

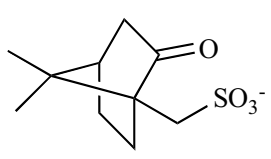

76

79

$-\mathrm{BF}_{4}$

83

Scheme 16. Excerpt from CIL-library for asymmetric aldol reaction [49]. 
Table 12. Aldol Reactions Catalyzed by the CILs (Selected Data) [49]

\begin{tabular}{|c|c|c|c|c|c|c|}
\hline Entry & Catalyst & t (h) & Yield (\%) & Anti/Syn & $e e$, anti $(\%)$ & $e e, \operatorname{syn}(\%)$ \\
\hline 1 & 83 & 30 & 92 & $46: 55$ & 26 & 71 \\
\hline 3 & 71 & 60 & 94 & $60: 40$ & 15 & 46 \\
\hline 4 & 74 & 36 & 97 & $60: 40$ & 21 & 6 \\
\hline 6 & 78 & 50 & 90 & $57: 43$ & 35 & 34 \\
\hline 8 & 80 & 23 & 94 & $70: 30$ & 55 & 73 \\
\hline
\end{tabular}

$\underset{\mathrm{CIL}}{\stackrel{\begin{array}{c}\text { Sharpless } \\ \text { dihydroxylation }\end{array}}{\longrightarrow}} \mathrm{R}_{\mathrm{R}}^{\mathrm{OH}} \begin{aligned} & \mathrm{R}=n-\mathrm{Bu}(\mathbf{8 5}), 95 \%, 85 \% e e \\ & \mathrm{R}=\mathrm{Ph}(\mathbf{8 6}), 92 \%, 72 \% e e\end{aligned}$

$\mathrm{CIL}(\mathrm{R}=n$-hexyl) $84=$

Scheme 17. Sharpless asymmetric dihydroxylation in CIL [21].

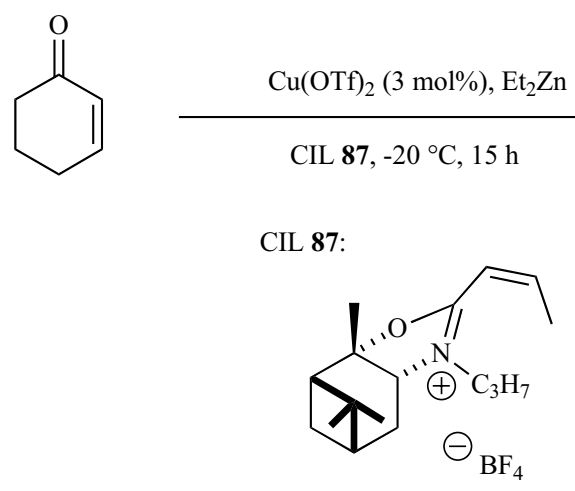

Scheme 18. Asymmetric copper-catalyzed diethyl zinc addition to enones (up to $76 \%$ ee) [22].

tably, the asymmetric dihydroxylation still gave high yields and moderate enantiomeric excesses $(40 \%$ ee) using catalytic amounts of the CIL 84 dissolved in $t-\mathrm{BuOH} / \mathrm{H}_{2} \mathrm{O}$. This result differs totally from those reported by $\mathrm{Vo}$-Thanh and Leitner, where only almost racemic material was obtained. The better results for the asymmetric dihydroxylation might be due to the strong electrostatic interaction and hydrogen bonding between the CIL, reactants and the catalyst.

Malhotra and Wang performed copper catalyzed enantioselective 1,4 addition of diethylzinc to enones [22]. Notably, the CIL 87 derived from the chiral pool contains the chirality in a cationic oxazolinium salt with a pinene backbone (Scheme 18). The investigators also observed that the concentration of the CIL 87 has an influence to the enantiomeric excess. With low catalytic amounts of the CIL 87 ( $<$ $10 \mathrm{~mol} \%$ ), the enantioselectivity was also low $(17-38 \%$ ee). Increasing the amount of CIL 87 to $35 \mathrm{~mol} \%$, the enanti- omeric excess rised up to $76 \%$ ee with cyclohexenone and cyclopentenone (Scheme 18, Table 13).

Table 13. Effect of CIL 87 (mol \%) on the Alkylation of Cyclohex-2-enone with Diethylzinc ${ }^{\text {a }}$ [22]

\begin{tabular}{|c|c|c|}
\hline Entry & CIL (mol\%) & $\boldsymbol{e e ~ ( \% )}$ \\
\hline \hline 1 & 3 & 17 \\
\hline 2 & 5 & 23 \\
\hline 3 & 10 & 38 \\
\hline 4 & 15 & 51 \\
\hline 5 & 25 & 74 \\
\hline 6 & 35 & $76^{*}$ \\
\hline
\end{tabular}

a $3 \mathrm{~mol} \% \mathrm{Cu}(\mathrm{OTf})_{2}, \mathrm{~T}=-20{ }^{\circ} \mathrm{C}, \mathrm{t}=15 \mathrm{~h} .{ }^{*}$ Conversion: $90 \%$. 
<smiles>[R]C(=C)C(C)=O</smiles><smiles>O=S(=O)(O)c1ccc(-c2ccccc2)c(-c2cc(S(=O)(=O)O)ccc2-c2ccccc2)c1</smiles>

BiPHEP-SO

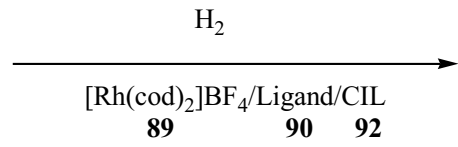

$89 \quad 90 \quad 92$<smiles>Ic1ccccc1-c1ccccc1-c1ccccc1</smiles>

BiPHEP<smiles>[R]C(C)C(C)=O</smiles>

93, 94

$\mathrm{R}=\mathrm{CH}_{2} \mathrm{CO}_{2} \mathrm{Me}$ (up to $29 \%$ ee): 94<smiles>CC(=O)[C@@H]1CCCN1</smiles>

92

Scheme 19. Rh-catalyzed hydrogenation in CIL 92 [53].

The authors believed that the chiral induction is due to the formation of a "chiral pocket" with the CIL and the $\mathrm{Cu}$ metal, influencing the selectivity of the alkyl transfer. They also observed that different achiral anions have a great influence to the enantiomeric excess $\left(\mathrm{BF}_{4}: 76 \%\right.$ ee, $\mathrm{PF}_{6}: 35 \%$ ee $)$. Noteworthy, the CIL can be used as additive or co-solvent in asymmetric catalysis.

In 2007, another enantioselective catalytic hydrogenation with an achiral transition metal catalyst was presented by Leitner and co-workers [53]. In contrast to the previously discussed hydrogenation of a prochiral ketone, here, acrylates are enantioselectively hydrogenated by a rhodium catalyst with achiral BiPHEP ligands (biphenylphosphine; e. g. 90) and CILs based on amino acids (Scheme 19). To enhance the solubility, and also for immobilization, anionic sulfonated ligands were used.

Furthermore, different additives were applied to optimize the enantiomeric excess. The highest value $69 \%$ ee was obtained using the BiPHEP-SO ${ }_{3}$ ligand 90, a proline based CIL 92 and triethylamine as basic additive. Instead, the addition of water gave a similar enantiomeric excess $(47 \%$ ee $)$ as without additive $(49 \%$ ee $)$, (see: Table 14).

Table 14. Selected Data for the Rh-catalyzed Hydrogenation of methyl 2-acetamidoacrylate in CIL 92 $^{\mathrm{a}}$ [53]

\begin{tabular}{|c|c|c|c|}
\hline Entry & Ligand & Additive & $\boldsymbol{e e ( \% )}$ \\
\hline \hline 1 & 90 & - & $49(S)$ \\
\hline 2 & - & - & $r a c$ \\
\hline 3 & 90 & $\mathrm{H}_{2} \mathrm{O}$ & $47(S)$ \\
\hline 4 & 90 & $\mathrm{NEt}_{3}$ & $69(S)$ \\
\hline 5 & 91 & $\mathrm{NEt}_{3}$ & $52(S)$ \\
\hline
\end{tabular}

${ }^{a}$ Substrate/cat $=250, p\left(\mathrm{H}_{2}\right)=40$ bar. Full conversion was achieved in all experiments unless otherwise noted. Conversion and enantioselectivity were determined by GC (Lipodex E).

They showed also that a base enhances collaborative effects in the catalytic system between the rhodium metal and the CIL 92, where neutral additives $\left(\mathrm{H}_{2} \mathrm{O}\right)$ and acids have no effects or gave lower enantiomeric excesses. Notably, also the non-sulfonated ligand BiPHEP 91 gave remarkable results $\left(52 \%\right.$ ee) when $\mathrm{NEt}_{3}$ was added. This indicates that the predominated asymmetric induction is not due to direct interaction of the ligand backbone with the CIL 92. It seems most likely the addition of base, free amino acid esters may act as monodentate $(\mathrm{N})$ or bidentate $(\mathrm{N}, \mathrm{O})$ ligand (from the CIL). Directly coordinating to the rhodium centre which allows asymmetric induction. In additional experiments, they showed that the catalytic system is recyclable at least over three runs, where the product was separated by extraction with supercritical $\mathrm{CO}_{2}$.

Recently, Leitner and co-workers presented their advances in rhodium complex catalyzed asymmetric hydrogenation of dimethyl itaconate $\left(\mathrm{R}=\mathrm{CH}_{2} \mathrm{CO}_{2} \mathrm{Me}\right)$ using CIL 92 as source of chirality (Scheme 20) [54]. The detailed investigations focused on applying rac-binap (rac-95), $(R)$ binap $(R-95)$ and $(S)$-binap $(S-95)$ as ligands for rhodium catalysis with $(S)$-proline methyl ester based CIL MeProl.NTf $\mathrm{NT}_{2} 92$ as co-solvent and source of chirality. Most interestingly all ligands showed similar selectivities for the hydrogenation of dimethyl itaconate $(64-71 \% e e)$, where with $(R)$-binap $R-95$ the $(R)$-enantiomer $(R-95)$ was obtained (Table 15).

They explained the almost identical selectivity using racbinap rac-95 and (S)-binap $S$-95 with chiral poisoning of the respective $\mathrm{Rh}$ /binap complexes with the (S)-proline-CIL 92. Where in the system with rac-binap (rac-95), the rhodium complex fragment with $(R)$-binap is more stable in presence of the (S)-proline-CIL 92 (as ligand) and consequently this complex is much less reactive than the $[\operatorname{Rh}\{(S)$-binap $\}]$ complex. Using the benchmark substrate methyl $\mathrm{N}$ acetamido acrylate $(\mathrm{R}=\mathrm{NH}(\mathrm{CO}) \mathrm{Me})$ the best selectivity reached $41 \%$ ee. Here, they showed the influence of the selectivity using $(R)$-binap $R \mathbf{- 9 5}$ and different ratios between $(S)$-proline-CIL 92 and the co-solvent dichloromethane.

The optically active orthopalladated phenanthrylamine phase transfer catalyst has been produced and explored for asymmetric glycine alkylation in CIL (Scheme 21) [55]. 
<smiles>[R]C(=C)C([R])=O</smiles><smiles>CC(C)(C)Br</smiles><smiles>[R]C(C)C(=O)OC</smiles>

$\mathrm{R}=\mathrm{NH}(\mathrm{CO}) \mathrm{Me}$ (up to $41 \% e e, \mathbf{8 9}$ ): $\mathbf{9 3}$

$\mathrm{R}=\mathrm{CH}_{2} \mathrm{CO}_{2} \mathrm{Me}(64-71 \% e e, \mathbf{9 6}, 97): 94$

95: rac-binap,

$(S)$ - or $(R)$-binap<smiles>c1ccc(-c2ccc3ccccc3c2-c2c(-c3ccccc3)ccc3ccccc23)cc1</smiles><smiles>COC(=O)[C@H]1CCCN1</smiles>

(MeProl.NTf 2 )

$[\mathrm{Rh}]=[\mathrm{Rh}(\mathrm{acac})(\mathrm{cod}) \quad 96$

$=\left[\mathrm{Rh}(\mathrm{acac})(\mathrm{CO})_{2}\right] \quad 97$

$=\left[\operatorname{Rh}(\operatorname{cod})_{2} \mathrm{BF}_{4} \quad 89\right.$

Scheme 20. Rh-catalyzed hydrogenation in CIL [54].

Table 15. Selected Data for the Rhodium-Catalyzed Asymmetric Hydrogenation of Dimethyl Itaconate ${ }^{\mathrm{a}}$ [54]

\begin{tabular}{|c|c|c|c|}
\hline Entry & Ligand 95 & [Rh] & ee (\%) \\
\hline \hline 1 & rac-binap & 96 & $67(S)$ \\
\hline 2 & rac-binap & 97 & $65(S)$ \\
\hline 3 & $(R)$-binap & 96 & $71(R)$ \\
\hline 4 & $(R)$-binap & 97 & $66(R)$ \\
\hline 5 & $(S)$-binap & 96 & $64(S)$ \\
\hline 6 & $(S)$-binap & 97 & $70(S)$ \\
\hline
\end{tabular}

${ }^{a}$ Reaction conditions: $[\mathrm{Rh}]=0.01 \mathrm{mmol}$, binap/[Rh] $=1: 1$, substrate/[Rh] $=300: 1, \mathrm{p}\left(\mathrm{H}_{2}\right)=40$ bar, $\operatorname{MeProl}_{\mathrm{NTf}} \mathbf{9 2}(0.2 \mathrm{~mL}), \mathrm{CH} \mathrm{Cl}_{2}(1 \mathrm{~mL}), 16 \mathrm{~h}, \mathrm{RT}$. Full conversion in all entries.<smiles>C[N+](C)(C)[C@@H](O)c1ccccc1</smiles>

98

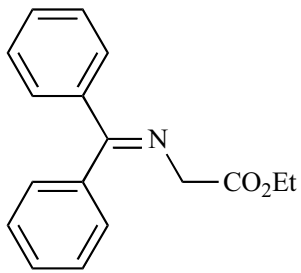<smiles>[X]OC(C)=O</smiles>

99<smiles>[X]Cc1ccccc1</smiles>

100

Scheme 21. Asymmetric alkylation reaction in CIL 98 using chiral orthopalladated phenanthrylamine $(\mathrm{R}=$ benzyl $)$ [55].

Apparently, the chiral ionic liquid 98 has a cooperative effect to boost the enantiomeric excess content of an asymmetric reaction. Yields were very good (85-92\%) and enantiomeric excesses fair (20-26\%). In organic solvents and non- chiral ILs, the $e e^{\prime}$ s were lower (9-16\%). Interestingly, the CIL can not alone induce enantioselectivity under biphasic conditions, it acts as a chiral booster to increase the ee when used along with the orthopalladated complex. 


\section{HETEROGENEOUS TRANSITION METAL CA- TALYSIS}

In 2007, the first paper dealing with a solid catalyst for heterogeneous asymmetric catalytic hydrogenation in CIL 101 was published by Wasserscheid et al. [17]. The authors performed ruthenium catalyzed $(\mathrm{Ru} / \mathrm{C})$ asymmetric hydrogenation of a prochiral imidazolium salt in presence of a chiral anion derived from the chiral pool (Scheme 22).

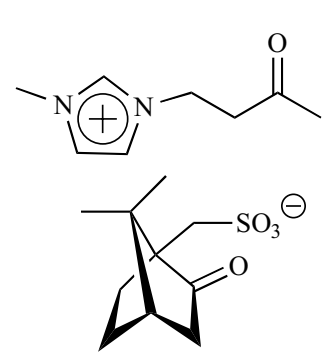

101

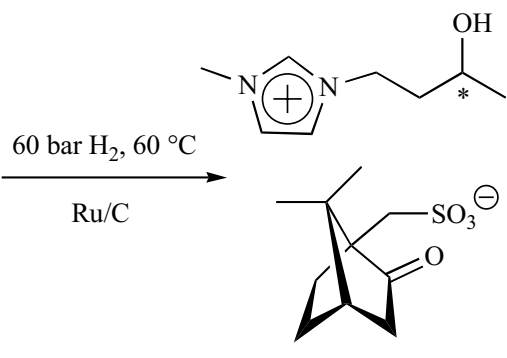

102
Scheme 22. Asymmetric hydrogenation of prochiral imidazolium cation with achiral solid ruthenium catalyst $(80 \%$ ee) [17].

The enantioselectivity reached $80 \%$ ee, where the reaction was performed in ethanol as solvent to decrease the viscosity of the CIL 101. In accordance to the previous results presented inhere, the higher the concentration of the source of chirality, the enantiomeric excess in the product. In their investigation of this reaction, they also excluded that the asymmetric induction might be due to chiral modification of the surface of the solid achiral $\mathrm{Ru} / \mathrm{C}$ catalyst. They pointed out that the effective asymmetric induction in this reaction must be based on strong ion-pairing effects between the chiral anion and the prochiral cation.

In 2009, Wasserscheid and co-workers published their extended studies on this issue, investigating some varying camphorsulfonate ILs with prochiral cations shown in Fig. (1) [56]. As noted before, the viscosity of the reaction plays a role, furthermore, the nature of solvent to decrease the viscosity, too. In most cases, the enantioselectivity was much better using ethanol as solvent than water. Comparing these solvent systems, this effect was explained by the higher dissociation of water, resulting in a different solvatization of the chiral ion pairs, than in ethanol. Thus, the ethanol-system is superior to the water-system. Furthermore, they found out that the concentration of CIL in the solvent plays an important role for the chirality transfer, where neither low nor very high concentrations are suitable for asymmetric induction in the cation. High concentrations result in ion cluster formation which suppresses the efficiency of the chirality transfer. Furthermore, the alkyl-chain length (spacer), where the prochiral centre is incorporated, plays an important role. The IL with a 2-butanone $\mathbf{1 0 1}$ side-chain was hydrogenated with 94\% ee, instead, a 2-hexanone side-chain in CIL 103 was hydrogenated with $45 \%$ ee under identical reaction conditions with $0.3[\mathrm{~mol} / \mathrm{L}] \mathrm{CIL}$ in ethanol, this concentration represents also the lowest degree of dissociation for these systems (Fig. (1), Table 16).

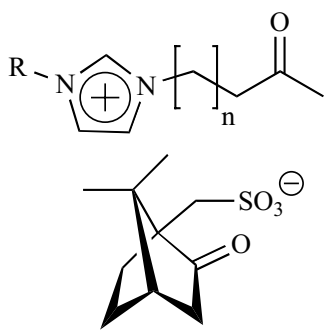

CIL 101: $\mathrm{n}=1, \mathrm{R}=\mathrm{Me}$ CIL 103: $\mathrm{n}=3, \mathrm{R}=\mathrm{Me}$ CIL 104: $n=1, R=H$

Fig. (1). Tested prochiral CILs 101, 103 and 104 [56].

In conclusion, the prochiral centre must be closed to the imidazolium cation (ionic centre) for an efficient chirality transfer from the chiral anion, using the ion-pairing effect, and the concentration of the CIL in the solvent should result in the lowest possible degree of dissociation.

Table 16. Selected Data for the Hydrogenation of Prochiral Cations Over Ru/C [56]

\begin{tabular}{|c|c|c|c|}
\hline Entry & CIL & Solvent & $\boldsymbol{e} \boldsymbol{\%}$ \\
\hline \hline 1 & $\mathbf{1 0 1}$ & EtOH & 94 \\
\hline 2 & $\mathbf{1 0 1}$ & Water & 4 \\
\hline 3 & $\mathbf{1 0 4}$ & EtOH & 54 \\
\hline 4 & $\mathbf{1 0 4}$ & Water & 38 \\
\hline 5 & $\mathbf{1 0 3}$ & EtOH & 45 \\
\hline 6 & $\mathbf{1 0 3}$ & Water & not given \\
\hline
\end{tabular}

Conditions: $\mathrm{T}=60^{\circ} \mathrm{C}, \mathrm{p}=60 \operatorname{bar}\left(\mathrm{H}_{2}\right), \mathrm{t}=15 \mathrm{~h}$,

$\mathrm{IL} /$ solvent $[\mathrm{mol} / \mathrm{L}]=0.3$, conversion $>95 \%$.

\section{DIELS-ALDER REACTION}

Moreover, we like to include outstanding examples which uses CILs in an asymmetric aza-Diels-Alder reaction [57]. Previous reports about asymmetric aza-Diels-Alder are generally promoted by chiral Lewis acid catalysts [57]. VoThanh and co-workers presented a reaction system without the need of (chiral) Lewis acid catalysts and organic solvents but recyclable chiral reaction medium. The diastereomeric excesses reached $72 \%$ de (yield: $30 \%$ ) or $66 \%$ de (yield: 77\%) (Scheme 23). As previously reported by Vo-Thanh in 2004 [19], and Leitner in 2006 [20], the presence of hydrogen bond donors, like hydroxy groups, enhance the reactivity and selectivity also in here, in the aza-Diels-Alder reaction.

Vo-Thanh and co-workers recently published further results with novel CIL about their asymmetric aza Diels-Alder reaction of Danishefsky's diene with some chiral imines (Scheme 23, Fig. (2)) [58, 59].

The strategy of using a CIL-containing a chiral moiety and a hydroxyl function derived from isosorbide being efficient to promote chiral induction in the aza Diels-Alder reactions. Yields ranged from 5-75\% and diastereomeric excesses from $32-69 \%$ de. Choosing $\mathrm{R}_{1}=\mathrm{R}_{2}=\mathrm{H}$, the authors obtained the products with $75 \%$ yield and $69 \%$ de. Additionally, the system could be reused at least four times without 


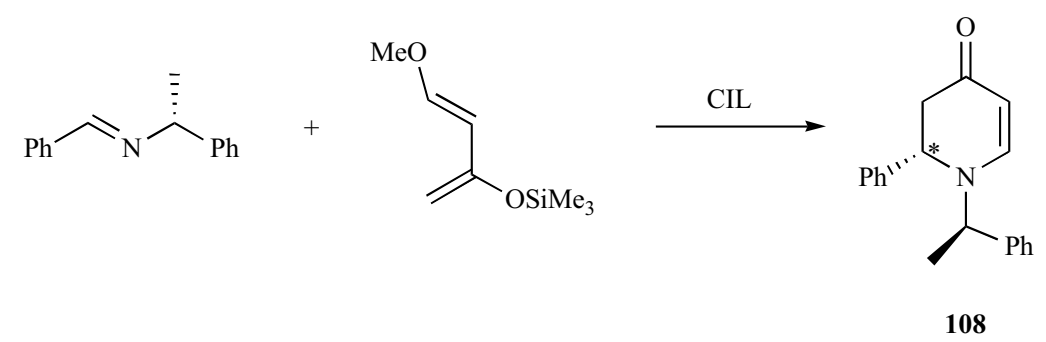

CIL:

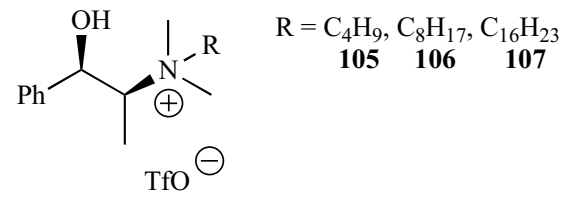

Scheme 23. Asymmetric aza-Diels-Alder reaction of Danishefsky's diene in CIL as source of chirality (72\% de) [57].

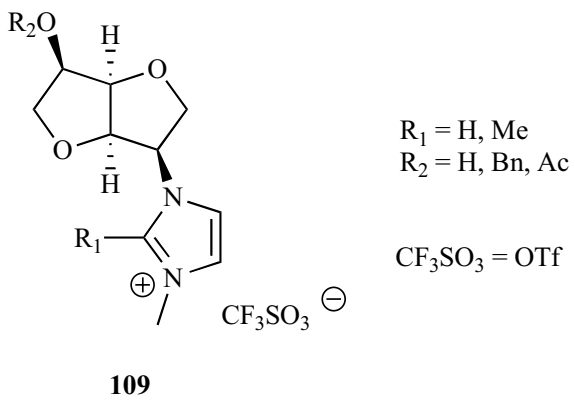

Fig. (2). Suitable CIL for Asymmetric aza Diels-Alder reaction (Scheme 23) [58].

loss of activity in recycling reactions. Other CILs for diastereoselective Diels-Alder reaction are camphor-based CILs [60].

\section{SUMMARY, CONCLUSIONS, OUTLOOK AND PERSPECTIVES}

In summary, the presented outstanding publications about asymmetric induction with chiral ionic liquids as single source of chiral information show similar conclusions in most cases concerning the question of chirality-transfer in CILs. Effective chirality transfer is based on strong electrostatic interaction, respectively ion-pairing effects and hydrogen bonding between the CILs and the reactants and/or catalysts. The activity and enantioselectivity is enhanced in presence of hydrogen bond donor groups such as hydroxy groups and the anion has in general a strong influence onto the chirality transfer. In certain cases using ion pairing effects, the concentration of the CIL in the co-solvent plays important role, where highest ee's are obtained with concentrations leading to the lowest degree of dissociation. Typical organocatalysts, such as proline-based systems, are immobilized in an alkyl side-chain or act as chiral counterion, usually anion. The potential for immobilized organocatalysts in CILs is very high, as it is reflected in most publications of that field since 2006. The advantage lies in the potential for recycling these ionic organocatalysts. Using CILs with organometallic catalysts is more difficult, and in this case, the CIL act as a chiral ligand for the organometallic precursor. Here, the enantioselectivity is assumably based on chiral poisoning, where one complex diastereomer is more stable (less reac- tive) than the other, thus an enantiomeric excess is reached. The disadvantage is, that the valuable CIL is used in large excess to induce chiral information. Presumably, this attempt will be rethought in future works, focusing more on welldefined chiral organometallic complexes incorporating (chiral) ionophilic ligands for the immobilization in ionic liquid media. Diels-Alder type reactions, represents the most challenging reactions using CILs as single source for asymmetric inductions. In such reaction (cyclo-additions, Enreaction, etc.) the CILs act as solvents and the asymmetric information is induced from the chiral solvent-environment of the $3 D$ IL-network (chiral folders, chiral pockets, etc.) onto the substrates (transition-state), giving diastereomeric excess in the corresponding products. Indeed, theses reactions can really be called solvent-induced asymmetric reactions. The first examples with solid state catalysts for heterogeneous catalysis assumed that the asymmetric induction relays on ion-pairing effects between the chiral anion and the cation (substrate). However, one can not exclude that the solid catalyst material serves as a reservoir for molecular complex species incorporating the chiral ion as ligand.

Without any doubt in the near future a full range of catalytic systems and more mechanistic details will be find in the literature about chiral ionic liquids for asymmetric catalysis. Until now, the transfer of chirality in ionic liquids is not clearly understood. The works in this review article, represents pioneering research in a quite young area, as many others, several decades ago, performed the first generation of classical homogeneous asymmetric catalysis with chiral ligand systems obtaining the first remarkable and high enantiomeric excesses [61].

\section{ACKNOWLEDGEMENT}

For financial support we gratefully acknowledge the Alexander-von-Humboldt-Foundation, CNPq and CAPES.

\section{REFERENCES}

[1] Schüth, F. Key technology of the chemical industry - Heterogenic catalysis. Chem. Unserer Zeit, 2006, 40, 92-103.

[2] Roos, G. H. Compendium of Chiral Auxiliary Applications, Academic Press: San Diego, 2001.

[3] Reichhardt, C. Solvents and Solvent Effects in Organic Chemistry, Wiley-VCH: Weinheim, 2003. 
[4] Bassindale, A. The third Dimension in Organic Chemistry, John Wiley and Sons: New York, 1984.

[5] Eliel, E. L.; Wilen, S. H. Stereochemistry of Organic Compounds, Wiley-Interscience: New York, 1994.

[6] Heitbaum, M.; Glorius, F.; Escher, I. Asymmetric heterogeneous catalysis. Angew. Chem. Int. Ed., 2006, 45, 4732-4762, Angew. Chem., 2006, 118, 4850-4881. And the references there in.

[7] Cornils, B.; Herrmann, W. A. Applied Homogeneous Catalysis with Organometallic Compounds, Wiley-VCH: Weinheim, 1996.

[8] Weingärtner, H. Understanding ionic liquids at the molecular level: Facts, problems, and controversies. Angew. Chem. Int. Ed., 2008, $47,654-670$

[9] Consorti, C. S.; Suarez, P. A. Z.; de Souza, R. F.; Burrow, R. A.; Farrar, D. H.; Lough, A. J.; Loh, W.; da Silva, L. H. M.; Dupont, J. Identification of 1,3-dialkylimidazolium salt supramolecular aggregates in solution. J. Phys. Chem. B, 2005, 109, 4341-4349.

[10] Wasserscheid, P.; Welton, T. Ionic Liquids in Synthesis, WileyVCH: Weinheim, 2003.

[11] Dupont, J.; Migowski, P. Catalytic applications of metal nanoparticles in imidazolium ionic liquids. Chem.-Eur. J., 2007, 13, 32-39.

[12] Lachwa, J.; Bento, I.; Duarte, M. T.; Lopes, J. N. C.; Rebelo, L. P. $\mathrm{N}$. Condensed phase behaviour of ionic liquid-benzene mixtures: congruent melting of a [emim] [NTf2]center dot C6H6 inclusion crystal. Chem. Commun., 2006, 2445-2447.

[13] Dupont, J.; Suarez, P. A. Z. Physico-chemical processes in imidazolium ionic liquids. Phys. Chem. Chem. Phys., 2006, 8, 24412452.

[14] For reviews about ILs in general: (a) Plechkova, N. V.; Seddon, K. R. Applications of ionic liquids in the chemical industry. Chem. Soc. Rev., 2008, 37, 123-150. (b) Tran, C. D. Ionic liquids for and by analytical Spectroscopy. Anal. Lett., 2007, 40, 2447-2464. (c) Polyakova, Y.; Koo, Y. M.; Row, K. H. Application of ionic liquids of some bioactive molecules in RP-HPLC. Rev. Anal. Chem., 2007, 26, 77-98. (d) Paczal, A.; Kotschy, A. Asymmetric synthesis in ionic liquids. Monatsh. Chem., 2007, 138, 1115-1123. (e) Nasirov, F. A.; Novruzova, F. M.; Aslanbeili, A. M.; Azizov, A. G. Ionic liquids in catalytic processes of transformation of olefins and dienes (Review). Petroleum Chem., 2007, 47, 309-317. (f) Liu, S. F.; Xiao, J. L. Toward green catalytic synthesis - Transition metalcatalyzed reactions in non-conventional media. J. Mol. Catal. A: Chem., 2007, 270, 1-43. (g) Li, Z. J.; Chang, J.; Shan, H. X.; Pan, J. $\mathrm{M}$. Advance of room temperature ionic liquid as solvent for extraction and separation. Rev. Anal. Chem., 2007, 26, 109-153. (h) Keskin, S.; Kayrak-Talay, D.; Akman, U.; Hortacsu, O. A review of ionic liquids towards supercritical fluid applications. J. Supercrit. Fluids, 2007, 43, 150-180. (i) Harjani, J. R.; Naik, P. U.; Nara, S. J.; Salunkhe, M. M. Enzyme mediated reactions in ionic liquids. $C$. Org. Synth., 2007, 4, 354-369. (j) Giernoth, R. Homogeneous catalysis in ionic liquids. In Situ NMR Methods Catal., 2007, 1-23. (k) Feher, E.; B. Major, B.; Belafi-Bako, K.; Gubicza, L. On the background of enhanced stability and reusability of enzymes in ionic liquids. Biochem. Soc. Trans., 2007, 35, 1624-1627.

[15] For reviews also discussing CILs: a) Welton, T. Room-temperature ionic liquids. Solvents for synthesis and catalysis. Chem. Rev., 1999, 99, 2071-2083. (b) Dupont, J.; de Souza, R. F.; Suarez, P. A. Z. Ionic liquid (molten salt) phase organometallic catalysis. Chem. Rev., 2002, 102, 3667-3691. (c) Baudequin, C.; Baudoux, J.; Levillain, J.; Cahard, D.; Gaumont, A.-C.; Plaquevent, J.-C. Ionic liquids and chirality: opportunities and challenges. Tetrahedron: Asymmetry, 2003, 14, 3081-3093. (d) Ding, J.; Armstrong, D. W. Chiral ionic liquids: Synthesis and applications. Chirality, 2005, 7, 281292. (e) Baudequin, C.; Brégeon, D.; Levillain, J.; Guillen, F.; Plaquevent, J.-C.; Gaumont, A.-C. Chiral ionic liquids, a renewal for the chemistry of chiral solvents? Design, synthesis and applications for chiral recognition and asymmetric synthesis. Tetrahedron Asymmetry, 2005, 16, 3921-3945. (f) Zhao, H.; Malhotra, S. V. Applications of ionic liquids in organic synthesis. Aldrichim. Acta, 2002, 35, 75-83. g) Chen, X. W.; Li, X. H.; Hu, A. X.; Wang, F. R. Advances in chiral ionic liquids derived from natural amino acids. Tetrahedron Asymmetry, 2008, 19, 1-14. h) Bica, K.; Gaertner, P. Applications of chiral ionic liquids. Eur. J. Org. Chem., 2008, 3235-3250. i) Patil, M.L.; Sasai H. Recent developments on chiral ionic liquids: Design, synthesis, and applications. Chem. Rec., 2008, 8, 98-108. j) Headley, A.D.; Ni B. Chiral imidazolium ionic liquids: Their synthesis and influence on the outcome of organic reactions. Aldrichim. Acta, 2007, 40, 107-117.
[16] a) Siyutkin, D. E.; Kucherenko, A. S.; Struchkova, M. I.; Zlotin, S. G. A novel (S)-proline-modified task-specific chiral ionic liquid an amphiphilic recoverable catalyst for direct asymmetric aldol reactions in water. Tetrahedron Lett., 2008, 49, 1212-1216. (b) Luo, S. Z.; Mi, X. L.; Zhang, L.; Liu, S.; Xu H.; Cheng, J. P. Functionalized ionic liquids catalyzed direct aldol reactions. Tetrahedron, 2007, 63, 1923-1930. (c) Luo, S. Z.; Zhang, L.; Mi, X. L.; Qiao, Y. P.; Cheng, J. P. Functionalized chiral ionic liquid catalyzed enantioselective desymmetrizations of prochiral ketones via asymmetric Michael addition reaction. J. Org. Chem., 2007, 72, 9350-9352.

[17] Schulz, P. S.; Muller, N.; Bosmann, A.; Wasserscheid, P. Effective chirality transfer in ionic liquids through ion-pairing effects. Angew. Chem. Int. Ed., 2007, 46, 1293-1295.

[18] Seebach, D.; Oei, H. A. Mechanism of electrochemical pinacolization - 1st asymmetric synthesis in a chiral medium. Angew. Chem. Int. Ed., 1975, 14, 634-635; Angew. Chem., 1975, 87, 629-630.

[19] Pégot, B.; Vo-Thanh, G.; Gori, D.; Loupy, A. First application of chiral ionic liquids in asymmetric Baylis-Hillman reaction. Tetrahedron Lett. 2004, 6425-6428.

[20] Gausepohl, R.; Buskens, P.; Kleinen, J.; Bruckmann, A.; Lehmann, C. W.; Klankermayer, J.; Leitner, W. Highly enantioselective AzaBaylis-Hillman reaction in a chiral reaction medium. Angew. Chem. Int. Ed., 2006, 45, 3689-3692; Angew. Chem. 2006, 118, 3772-3775.

[21] Bruno, L. C.; Gois, P. M. P.; Lourenço, N. H. T.; Kurteva, V. B.; Afonso, C. A. M. Simple transformation of crystalline chiral natural anions to liquid medium and their use to induce chirality. Chem. Commun., 2006, 2371-2373.

[22] Malhotra, S. V.; Wang, Y. Application of chiral ionic liquids in the copper catalyzed enantioselective 1,4-addition of diethylzinc to enones. Tetrahedron Asymmetry, 2006, 17, 1032-1035.

[23] Luo, S.; Mi, X.; Zhang, L.; Liu, S.; Cheng, J.-P. Functionalized chiral ionic liquids as highly efficient asymmetric organocatalysts for Michael addition to nitroolefins. Angew. Chem. Int. Ed., 2006, 45, 3093-3097; Angew. Chem., 2006, 118, 3165-3169.

[24] Tran, C. D.; Mejac, I. Chiral ionic liquids for enantioseparation of pharmaceutical products by capillary electrophoresis. J. Chromatogr. A, 2008, 1204, 204-209.

[25] Wang, C. F.; Zheng, Y. F.; Cai, S. L.; Ma, J. T.; Li, R. The effect of chiral solvent and various kinds of chiral organic salts on the asymmetric hydrogenation of methyl acetoacetate over improved taratraic acid modified raney nickel catalyst. React. Kinetics Catal. Lett., 2008, 95, 129-134.

[26] Hyun, M. H.; Kim, S. N.; Choi, H. J.; Sakthivel, P. Preparation and application of a new ion-pairing chiral stationary phase for the liquid chromatographic resolution of $\mathrm{N}$-(3,5-dinitrobenzoyl)-alphaamino acids. J. Liqu. Chromat. Rel. Technol., 2008, 31, 2363-2374.

[27] Bwambok, D. K.; Marwani, H. M.; Fernand, V. E.; Fakayode, S. O.; Lowry, M.; Negulescu, I.; Strongin, R. M.; Warner, I. M. Synthesis and characterization of novel chiral ionic liquids and investigation of their enantiomeric recognition properties. Chirality, 2008, 20,151-158.

[28] Adhikary, R.; Bose, S.; Mukherjee, P.; Thite, A.; Kraus, G. A.; Wijeratne, A. B.; Sharma, P. S.; Armstrong, D. W.; Petrich, J. W. Influence of chiral ionic liquids on the excited-state properties of naproxen analogs. J. Phys. Chem. B, 2008, 112, 7555-7559.

[29] Bregeon, D.; Levillain, J.; Guillen, F.; Plaquevent, J. C.; Gaumont, A. C. Thiazolinium and imidazolium chiral ionic liquids derived from natural amino acid derivatives. Amino Acids, 2008, 35, 175184.

[30] Matos, R. A. F.; Andrade, C. K. Z. Synthesis of new chiral ionic liquids based on (-)-menthol and (-)-borneol Tetrahedron Lett., 2008, 49, 1652-1655.

[31] Gao, H. S.; Hu, Z. G.; Wang, J. J.; Qiu, Z. F.; Fan, F. Q. Synthesis and properties of novel chiral ionic liquids from L-proline. Austr. J. Chem., 2008, 61, 521-525.

[32] Swatloski, R. P.; Holbrey, J. D.; Rogers, R. D. Ionic liquids are not always green: hydrolysis of 1-butyl-3-methylimidazolium hexafluorophosphate. Green Chem., 2003, 5, 361-363.

[33] a) Shi, M.; Chen, L.-H.; Li, C.-Q. Chiral phosphine lewis bases catalyzed asymmetric aza-Baylis-Hiliman reaction of $\mathrm{N}$-sulfonated imines with activated olefins J. Am. Chem. Soc., 2005, 127, 37903800. b) Matsui, K.; Takizawa, S.; Sanai, H. Bifunctional organocatalysts for enantioselective aza-Morita-Baylis-Hillman reaction. J. Am. Chem. Soc., 2005, 127, 3680-3681. 
[34] Garre, S.; Parker, E.; Ni, B. K.; Headley, A. D. Design and synthesis of bistereogenic chiral ionic liquids and their use as solvents for asymmetric Baylis-Hillman reactions. Org. Biomol. Chem., 2008, 6, 3041-3043.

[35] Ni, B.; Zhang, Q.; Headley, A. D. Functionalized chiral ionic liquid as recyclable organocatalyst for asymmetric Michael addition to nitrostyrenes. Green Chem., 2007, 9, 737-739.

[36] Qian, Y. B.; Xiao, S. Y.; Liu, L.; Wang, Y. M. A mild and efficient procedure for asymmetric Michael additions of cyclohexanone to chalcones catalyzed by an amino acid ionic liquid. TetrahedronAsymmetry, 2008, 19, 1515-1518.

[37] Ni, B. K.; Zhang, Q. Y.; Headley, A. D. Pyrrolidine-based chiral pyridinium ionic liquids (ILs) as recyclable and highly efficient organocatalysts for the asymmetric Michael addition reactions. Tetrahedron Lett., 2008, 49, 1249-1252.

[38] Ni, B. K.; Zhang, Q. Y.; Dhungana, K.; Headley, A. D. Ionic liquid-supported (ILS) (S)-pyrrolidine sulfonamide, a recyclable organocatalyst for the highly enantioselective Michael addition to nitroolefins. Org. Lett., 2009, 11, 1037-1040.

[39] Zhang, Q. Y.; Ni, B. K.; Headley, A. D. Asymmetric Michael addition reactions of aldehydes with nitrostyrenes catalyzed by functionalized chiral ionic liquids. Tetrahedron, 2008, 64, 5091-5097.

[40] Li, P. H.; Wang, L.; Wang, M.; Zhang, Y. C. Polymer-immobilized pyrrolidine-based chiral ionic liquids as recyclable organocatalysts for asymmetric Michael additions to nitrostyrenes under solventfree reaction conditions. Eur. J. Org. Chem., 2008, 1157-1160.

[41] Li, P. H.; Wang, L.; Zhang, Y. C.; Wang, G. W. Silica gel supported pyrrolidine-based chiral ionic liquid as recyclable organocatalyst for asymmetric Michael addition to nitrostyrenes. Tetrahedron, 2008, 64, 7633-7638.

[42] Ou, W.-H.; Huang, Z. Z. An efficient and practical synthesis of chiral imidazolium ionic liquids and their application in an enantioselective Michael reaction. Green Chem., 2006, 8, 731-734.

[43] Wang, Z. M.; Wang, Q.; Zhang, Y.; Bao, W. L. Synthesis of new chiral ionic liquids from natural acids and their applications in enantioselective Michael addition. Tetrahedron Lett., 2005, 46, 4657-4660.

[44] Miao, T.; Wang, L.; Li P. H.; Yan J. C. A highly efficient and recyclable ionic liquid anchored pyrrolidine catalyst for enantioselective Michael additions. Synthesis, 2008, 23, 3828-3834.

[45] Miao, W.; Chan, T. H. Ionic-liquid-supported organocatalyst: Efficient and recyclable ionic-liquid-anchored proline for asymmetric aldol reaction. Adv. Synth. Catal., 2006, 348, 1711-1718.

[46] Siyutkin, D. E.; Kucherenko, A. S.; Zlotin, S. G. Hydroxy-alphaamino acids modified by ionic liquid moieties: recoverable organocatalysts for asymmetric aldol reactions in the presence of water. Tetrahedron, 2009, 65, 1366-1372.

[47] Siyutkin, D. E.; Kucherenko, A. S.; Struchkova, M. I.; Zlotin, S. G., A novel (S)-proline-modified task-specific chiral ionic liquid an amphiphilic recoverable catalyst for direct asymmetric aldol reactions in water. Tetrahedron Lett., 2008, 49, 1212-1216.

[48] Pinto, A. C.; Lapis, A. A. M.; da Silva, B. V.; Bastos, R. S.; Dupont, J.; Neto, B. A. D. Pronounced ionic liquid effect in the synthesis of biologically active isatin-3-oxime derivatives under acid catalysis. Tetrahedron Lett., 2008, 49, 5639-5641.
[49] Zhang, L.; Luo, S. Z.; Mi, X. L.; Liu, S.; Qiao, Y. P.; Xu, H.; Cheng, J. P. Combinatorial synthesis of functionalized chiral and doubly chiral ionic liquids and their applications as asymmetric covalent/non-covalent bifunctional organocatalysts. Org. Biomol. Chem., 2008, 6, 567-576.

[50] Lombardo, M.; Pasi, F.; Easwar S. Trombini C. Direct asymmetric aldol reaction catalyzed by an imidazolium-tagged trans-4Hydroxy-L-proline under aqueous biphasic conditions. Synlett, 2008, 16, 2471-2474.

[51] Zhou, W.; Xu, L. W.; Qiu, H. Y.; Lai G. Q.; Xia C. G.; Jiang J. X. Synthesis of a novel chiral ionic liquid and its application in enantioselective aldol reactions. Helv. Chim. Acta, 2008, 91, 53-59.

[52] Afonso, C. A. M.; Branco, L. C.; Candeais, N. R.; Gois, P. M. P.; Lourenço, N. M. T.; Mateus, N. M. M.; Rosa, J. N. Efficient catalyst reuse by simple dissolution in non-conventional media. Chem. Commun., 2007, 2669-2679.

[53] Schmitkamp, M.; Chen, D.; Leitner, W.; Klankermayer, J.; Franciò, G. Enantioselective catalysis with tropos ligands in chiral ionic liquids. Chem. Commun., 2007, 4012-4014.

[54] Chen, D.; Schmitkamp, M.; Franciò, G.; Klankermayer, J.; Leitner., W. Enantioselective hydrogenation with racemic and enantiopure binap in the presence of a chiral ionic liquid. Angew. Chem., 2008, 120, $7449-7451$

[55] Mukherjee, D. K.; Ghosh, N. Enantio selective phase transfer alkylation using orthopalladated complex in chiral ionic liquid. Catal. Commun., 2008, 9, 40-44.

[56] Schneiders, K.; Boesmann, A.; Schulz, P. S.; Wasserscheid, P. Chirality transfer in imidazolium camphorsulfonate ionic liquids through ion pairing effects. Adv. Synth. Catal., 2009, 351, 432-440.

[57] Pégot, B.; Van Buu, O. N.; Gori, D.; Vo-Thanh, G. Asymmetric aza-Diels-Alder reaction of Danishefsky's diene with imines in a chiral reaction medium. Beilstein J. Org. Chem., 2006, 2, article-no 18. doi: 10.1186/1860-5297-2-18.

[58] Van Buu, O. N.; Aupoix, A.; Vo-Thanh, G. Synthesis of novel chiral imidazolium-based ionic liquids derived from isosorbide and their applications in asymmetric aza Diels-Alder reaction. Tetrahedron, 2009, 65, 2260-2265.

[59] Van Buu, O. N.; Vo-Thanh, G. Synthesis of novel chiral ammonium-based ionic liquids derived from hosorbide and their applications in an asymmetric aza Diels-Alder reaction. Lett. Org. Chem., 2007, 4, 158-167.

[60] Bica, K.; Gmeiner, G.; Reichel, C.; Lendl, B.; Gaertner, P. Microwave-assisted synthesis of camphor-derived chiral imidazolium ionic liquids and their application in diastereoselective Diels-Alder reaction. Synthesis, 2007, 1333-1338.

[61] Nobel lectures 2001 about asymmetric catalysis: a) Knowles, W. S. Asymmetric hydrogenations (Nobel lecture). Angew. Chem. Int. Ed., 2002, 1998-2007; Angew. Chem., 2002, 114, 2096-2107. b) Noyori, R. Asymmetric catalysis: Science and opportunities (Nobel lecture). Angew. Chem. Int. Ed., 2002, 2008-2022, Angew. Chem., 2002, 114, 2108- 2123. c) Sharpless, K. B. Searching for new reactivity (Nobel lecture). Angew. Chem. Int. Ed., 2002, 2024-2032; Angew. Chem., 2002, 114, 2126-2135. 